\title{
Design and Characterization of Spray-Dried Proliposomes for the Pulmonary Delivery of Curcumin
}

This article was published in the following Dove Press journal: International Journal of Nanomedicine

\author{
Islam M Adel (D) \\ Mohamed F EIMeligy' \\ Mohamed EA Abdelrahim (iD) ${ }^{2}$ \\ Amr Maged (D) 3 , \\ AbdelFattah A Abdelkhalek ${ }^{5}$ \\ Azza MM Abdelmoteleb ${ }^{6}$ \\ Nermeen A Elkasabgy (D) \\ 'Department of Pharmaceutics and \\ Industrial Pharmacy, Faculty of Pharmacy, \\ Cairo University, Cairo, II 562, Egypt; \\ ${ }^{2}$ Clinical Pharmacy Department, Faculty \\ of Pharmacy, Beni-Suef University, Beni- \\ Suef, Egypt; ${ }^{3}$ Department of \\ Pharmaceutics and Pharmaceutical \\ Technology, Faculty of Pharmaceutical \\ Sciences and Pharmaceutical Industries, \\ Future University in Egypt, Cairo, Egypt; \\ ${ }^{4}$ Pharmaceutical Factory, Faculty of \\ Pharmaceutical Sciences and \\ Pharmaceutical Industries, Future \\ University in Egypt, Cairo, Egypt; \\ ${ }^{5}$ Department of Microbiology of \\ Supplementary General Science, Faculty \\ of Oral \& Dental Medicine, Future \\ University in Egypt, Cairo, Egypt; \\ ${ }^{6}$ Department of Chemistry, Toxicology \\ and Feed Deficiency, Animal Health \\ Research Institute, Agricultural Research \\ Center, Giza, Egypt
}

Purpose: The goal was to directly deliver curcumin, a natural polyphenolic anticancer and anti-inflammatory compound, to the lung tissues with minimal systemic exposure through the fabrication of proliposomes, overcoming its poor aqueous solubility and oral bioavailability. Methods: Nano-spray drying was employed to prepare proliposomes using hydroxypropyl betacyclodextrin as a carrier. Lecithin and cholesterol were used as lipids, stearylamine and Poloxamer 188 were added as positive charge inducer and a surfactant, respectively. Different characterization parameters were evaluated like percentage yield, entrapment efficiency, drug loading, aerodynamic particle size, in vitro release besides morphological examination. Cytotoxicity studies on cell line A549 lung tumor cells as well as in vivo lung pharmacokinetic studies were also carried.

Results: The optimized formulations showed superior aerosolization properties coupled their enhanced ability to reach deep lung tissues with a high \% of fine particle fraction. Cytotoxicity studies using MTT assay demonstrated enhanced growth inhibitory effect on lung tumor cells A549 and significant reduction of proinflammatory cytokines such as tumor necrosis factor- $\alpha$, interleukin- 6 and interleukin-10 compared to the pure drug. Results of lung pharmacokinetic tests confirmed the superiority of proliposomal curcumin over curcumin powder in both, the rate and extent of lung tissue absorption, as well as the mean residence time within the lung tissues.

Conclusion: The pulmonary delivery of curcumin-loaded proliposomes as dry powder provides a direct approach to lung tissues targeting while avoiding the limitations of the oral route and offering a non-invasive alternative to the parenteral one.

Keywords: curcumin, proliposomes, cyclodextrin, dry powder inhalers, human epithelial cell line, pulmonary delivery

\section{Introduction}

Cancer is one of the leading hazardous and life-threatening diseases to ever-present. Despite recent advances in cancer diagnosis and therapy, it is still held responsible for the second highest rates of deaths among other diseases. ${ }^{1}$ Lung cancer, not only the most common type of cancers but also accounts for the greatest mortality among them all. $^{2,3}$ Lung cancer could be either small-cell lung cancer (SCLC) or, more commonly ( $85 \%$ occurrence), non-small-cell lung cancer (NSCLC). ${ }^{4}$ There is a complex interplay between cancer and chronic inflammation. Clinical studies suggested that chronic airway inflammation causes airway remodeling with epithelial cell mutations and provide a suitable environment for lung carcinogenesis. ${ }^{5}$ Also, the release of the angiogenic, anti-apoptotic cytokines; interleukin-6 (IL-6) and interleukin-10 (IL-10)
Correspondence: Islam M Adel Faculty of Pharmacy, Cairo University, Kasr El-Aini Street, Cairo, I I562, Egypt Tel +20 I2264455 I I

Email islam.hashim@pharma.cu.edu.eg
International Journal of Nanomedicine 2021:16 2667-2687 
as a response anti-inflammatory mechanism is favorable for tumor progression. ${ }^{6}$ On the other hand, tumors are believed to induce inflammation. ${ }^{7}$ Cancers express cytokines that initiate inflammatory response and allocate neutrophils on site, referred to as Tumor-infiltrated lymphocytes. ${ }^{8}$ Also, cancer itself causes physical cell damage which initiates inflammatory response. ${ }^{9}$ Finally, cancers might compress blood vessels, limiting nutrient and oxygen supply resulting in the release of angiogenic growth factors, recruiting new blood vessels and more macrophages. ${ }^{10}$ Hence, antiinflammatory therapy could be beneficial in both preventive and curative approaches in cancer-susceptible and cancerplagued patients.

Various approaches are available for the treatment of primary lung cancer. Cancer chemotherapy, surgical tumor removal and radiation therapy are mostly used. ${ }^{4}$ Conventional drug delivery routes such as intravenous injections and oral delivery are used but present systemic side effects due to limitations of the routes themselves. ${ }^{11}$ Inhalation route proves superior in offering a more targeted approach and thus, avoiding possible systemic exposure and systemic side effects. ${ }^{11}$ Dry powder inhalers (DPIs) offer feasible means of drug delivery to the deep lung tissues and lower airways while ensuring the drug remains stable for long periods of storage, unlike other pulmonary inhalers and nebulizers, due to being in dry powder form. ${ }^{4,11}$

Besides chemical anticancer agents, several agents isolated from natural origins are proved to be effective as add-on therapy. Curcumin is an example of a natural anticancer agent. Curcumin is a polyphenolic molecule extracted from the rhizomes of Curcuma longa, which was, and still being, heavily studied over the last few years. Along with its anticancer activity, curcumin also possesses anti-oxidant, immunoregulatory and anti-inflammatory activities. ${ }^{12,13}$ It is effective in a wide array of cancers including lung cancer, breast cancer, hematological cancers, prostate cancer, colorectal cancers and hepatic cancer. ${ }^{14}$ Curcumin is thought to be interfering with signaling pathways involved in cancer tissue development. Besides that, it also downregulates the antiapoptotic proteins and upregulates the pro-apoptotic ones. This dual action helps contain cancer tissues and prevents it from further metastasis. ${ }^{14,15}$ In addition to its anticancer activity, the anti-inflammatory activity is extremely beneficial in cancer treatment. It exerts its anti-inflammatory action through inhibiting the production of the major involved proinflammatory cytokines like tumor necrosis factor- $\alpha$ (TNF- $\alpha$ ), IL-6 and IL-10. ${ }^{16,17}$ It was also found to induce neutrophils apoptosis. ${ }^{18}$ Despite the former beneficial activities of curcumin that enables it to be used either alone or as adjunct therapy in cancer, serious drawbacks limit its successful application. Low aqueous solubility $(11 \mathrm{ng} / \mathrm{mL}$ at $25^{\circ} \mathrm{C}$ ), high photosensitivity, rapid in vivo metabolism and poor cellular uptake severely limit its bioavailability. ${ }^{13,19}$ Encapsulation of curcumin within liposomes seemed to have solved most of the previous drawbacks. Liposomes are lipid vesicles composed of phospholipid bilayer structure engulfing an aqueous core. By the look of it, both hydrophilic and hydrophobic drugs can be incorporated successfully within liposomes, either in the aqueous center or in the phospholipid bilayer membranes, respectively. ${ }^{4}$ Large-scale production of liposomes is not feasible due to the high costs of the upscaling process. ${ }^{20}$ Liposomes also suffer from being relatively unstable colloidal systems. ${ }^{21}$ Both, the high costs and stability concerns of liposomes were solved by the introduction of the concept of proliposomes. Proliposomes are completely dry, free-flowing powders made of lipid vesicles engulfing the drug in question within its bilayer structure. ${ }^{22}$ Since proliposomes are collected and stored in dry condition, they offer higher stability profiles than other lipid solutions/ suspensions. ${ }^{13}$ Being in dry powder form, proliposomes facilitate product transfer and storage which lowers costs needed otherwise. ${ }^{21}$ Proliposomes undergo a rapid and easy hydration step, under controlled conditions of temperature and agitation, to turn into liposomes. Within the aqueous environment of the lungs, proliposomes are easily hydrated and exert their action locally or, if needed, rapidly absorbed and enters the systemic circulation.

In this study, curcumin-loaded proliposomes were prepared by nano-spray dryer using lecithin and cholesterol as vesicle matrix components, stearyl amine (SA) as a positive charge inducer, poloxamer 188 (PLX 188) as a surfactant and hydroxypropyl-beta-cyclodextrin (HP $\beta C D$ ) as a carrier to produce freely flowing powders. The prepared formulations were evaluated for their percentage yield, particle size, zeta potential, encapsulation efficiency and in vitro drug release. Morphological characters as well as aerodynamic particle size were assessed. Cytotoxicity of the chosen formulations as well as their effect on proinflammatory cytokines was examined against A-549 cell line.

\section{Materials and Methods}

\section{Materials}

Curcumin was kindly gifted by Guangzhou Phytochem Sciences Inc., China. Lecithin was brought from Fischer Scientific, USA. Cholesterol, stearylamine (SA), 
poloxamer 188 (PLX 188) and 2-hydroxypropyl- $\beta$ cyclodextrin (HP $\beta C D$ ) and dialysis tubing cellulose membrane (molecular weight cutoff $14,000 \mathrm{~g} / \mathrm{mol}$ ) were procured from Sigma-Aldrich, St. Louis, USA. Methanol and acetonitrile, HPLC grade, were bought from SigmaAldrich, UK.

The rest of the reagents were of analytical grade and used as received.

\section{Preparation of Spray-Dried Curcumin-Loaded Proliposomes (SD/P)}

Spray-dried curcumin-loaded proliposomes $(\mathrm{SD} / \mathrm{P})$ were prepared using a nano-spray dryer (Buchi ${ }^{\circledR}$ nano-spray dryer B-90, Büchi Labortechnik, Switzerland) similar to the technique used in previous work with some modifications. ${ }^{23}$ For the preparation of SD/P, different components were used. Different ratios of lecithin and cholesterol were tried as follows: 1:1, 2:1 and 3:1 w/w calculated on molar basis with regard to the total lipid content $(200 \mathrm{mg})$. SA was used as a cationic surface charge modifier and PLX 188 as a surfactant. Furthermore, HP $\beta C D$ was added as a carrier for the preparation of dry particles through the nano-spray dryer. Definite amounts of curcumin were added (20 mg). SD/P were prepared by dissolving the individual components in dehydrated ethanol $(20 \mathrm{~mL})$ by vortexing (Reax Top Vortex Mixer, Heidolph, Germany) for $30 \mathrm{sec}$. The composition of the prepared $\mathrm{SD} / \mathrm{P}$ is collected in Table 1. Following, the formed solutions were sprayed through the nano-spray dryer equipped with a vibration mesh spray with mean pore size equals to $7.0 \mu \mathrm{m}$. The solutions were introduced with a feeding rate of $25 \mathrm{~mL} / \mathrm{h}$. Nitrogen flow rate was $90 \mathrm{~L} / \mathrm{min}$. Inlet and outlet temperatures were kept at 90 and $45^{\circ} \mathrm{C}$, respectively. The prepared $\mathrm{SD} / \mathrm{P}$ were retrieved from the drying chamber and kept in desiccators at room temperature pending for more studies.

\section{Preparation of Improved Spray-Dried Curcumin-Loaded Proliposomes (SD/P)}

Improved spray-dried proliposomes were prepared following the same steps as in the previous section but using higher amounts of the carrier (HP $\beta C D ; 2 \mathrm{~g}$ ) for comparison purposes (Table 1).

\section{Characterization of the Prepared} Spray-Dried Curcumin-Loaded Proliposomes (SD/P)

\section{Determination of Percentage Yield}

$\%$ yield of the prepared SD/P was calculated from the ratio of the weight of the collected powder after spray-drying to the initial weights of solid components introduced in the feed solution, as shown by the equation:

$$
\begin{gathered}
\% \text { Yield }=(\text { Weight of collected powder } / \text { Initial } \\
\text { solid weight }) \times 100
\end{gathered}
$$

\section{Particle Size (PS), Polydispersity Index (PDI) and Zeta Potential (ZP) Analysis}

PS of the prepared SD/P was assessed using ZetaSizer Nano ZS (Malvern Instruments, Worcestershire, UK). Samples were, first, adequately diluted with phosphate buffer; pH 7.4 till the formation of faint opalescence, then PS was assayed. For assessing the particle size distribution, the PDI was determined. Furthermore, the ZP of the diluted samples was assessed to determine the surface charge of the particles.

\section{Drug Content (\% DC) and Drug Loading (\% DL)}

Accurately measured weights of $\mathrm{SD} / \mathrm{P}$ were dissolved in $95 \%$ ethanol. Following, the formed solution was analyzed for curcumin content at wavelength of $425 \mathrm{~nm}$ using Shimadzu UV Spectrophotometer (model UV-1601 PC; Shimadzu, Kyoto, Japan). The drug content and drug loading were determined from the succeeding equations:

$\%$ Drug content $=\begin{aligned} & (\text { Actual drug amount } / \text { Added } \\ & \text { drug amount }) \times 100\end{aligned}$

$\%$ Drug loading $=\begin{aligned} & \text { (Amount of drug in proliposomes } / \\ & \text { Weight of proliposomes }) \times 100\end{aligned}$

\section{Entrapment Efficiency (EE)}

Weights from the investigated SD/P equivalent to $0.1 \mathrm{mg}$ curcumin were reconstituted in $2 \mathrm{~mL}$ phosphate buffer $\mathrm{pH}$ 7.4, vortexed for $3 \mathrm{~min}$. The diluted liposomal dispersion was centrifuged (Model 8880, Centurion Scientific Ltd., W. Sussex, UK) at $16,000 \mathrm{rpm}$ for $45 \mathrm{~min}$ at $4^{\circ} \mathrm{C}$. The separated liposomes were washed twice with buffer, followed by dissolving the residue in certain volume of 


\begin{tabular}{|c|c|c|c|}
\hline & & 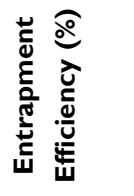 & 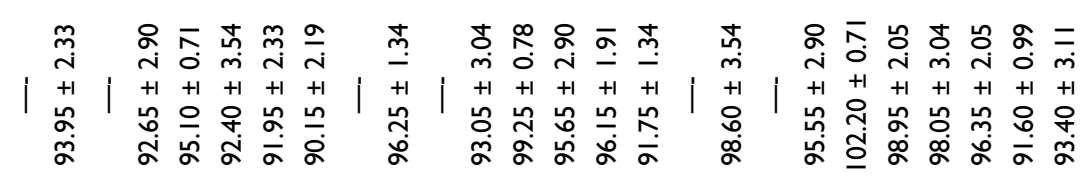 \\
\hline \multirow{6}{*}{\multicolumn{2}{|c|}{ Uू }} & 文 &  \\
\hline & & @o & 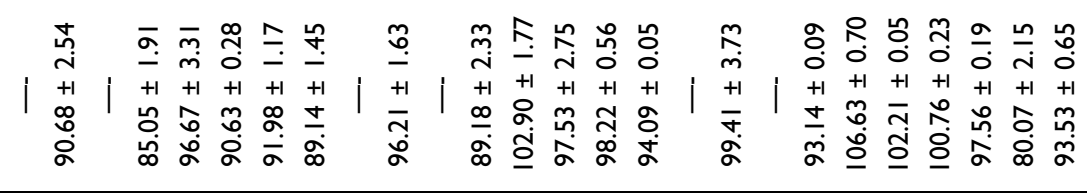 \\
\hline & & 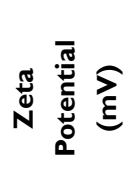 & 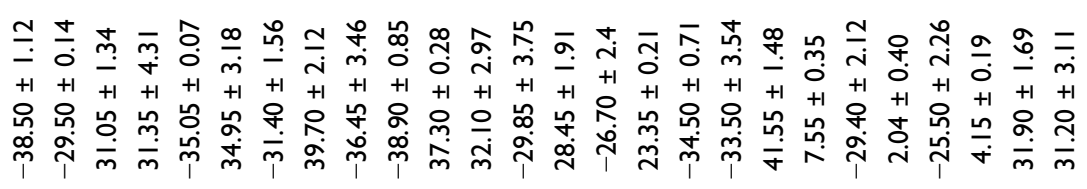 \\
\hline & & $\overline{0}$ & 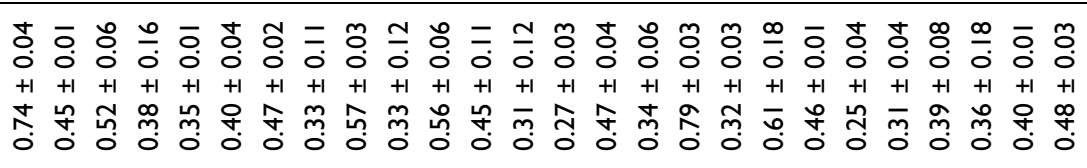 \\
\hline & & 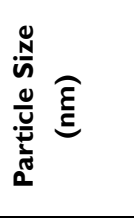 & 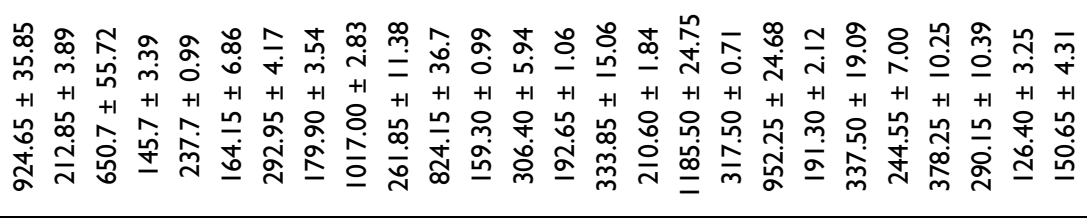 \\
\hline & & $\begin{array}{l}\overparen{\varrho} \\
\text { o }\end{array}$ & 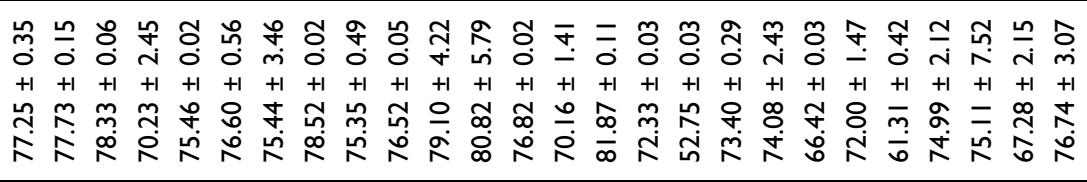 \\
\hline \multirow{3}{*}{\multicolumn{2}{|c|}{ 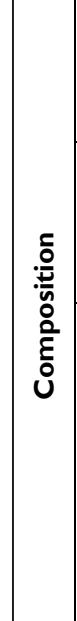 }} & $\frac{0}{\frac{0}{2}}$ & 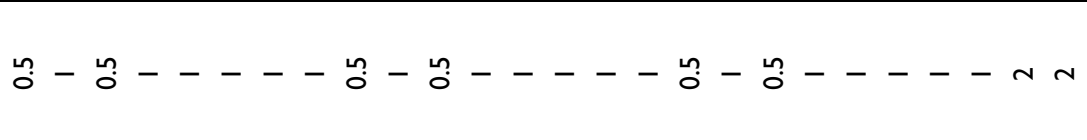 \\
\hline & & $\stackrel{\infty}{\underset{\infty}{x}} \underset{\vec{a}}{\stackrel{\infty}{\xi}}$ & 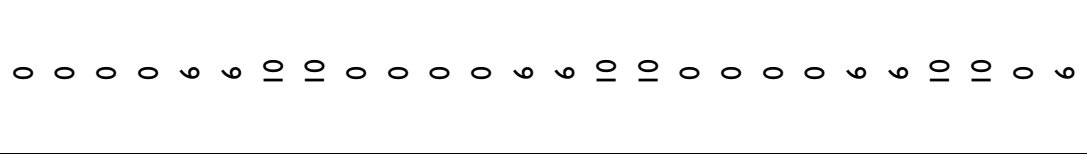 \\
\hline & & 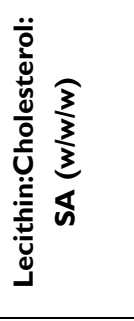 & 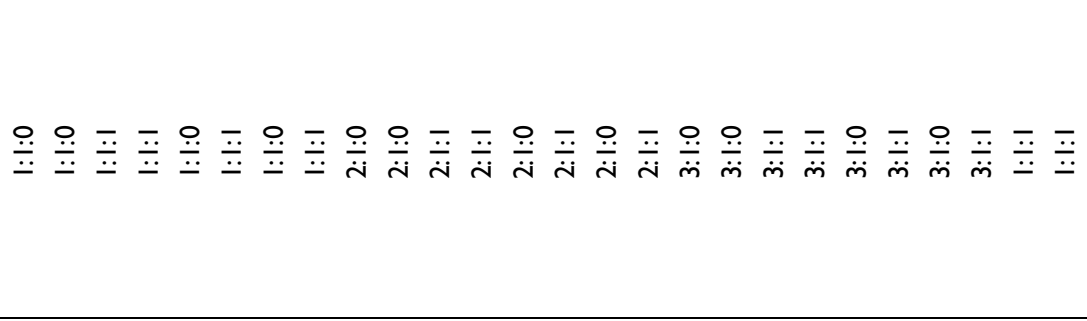 \\
\hline \multicolumn{3}{|c|}{ 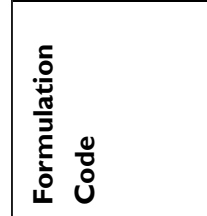 } & 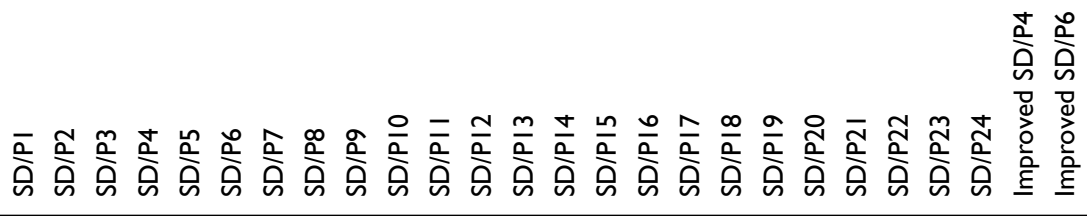 \\
\hline
\end{tabular}


ethanol by sonication $(10 \mathrm{~mL})$ at $37{ }^{\circ} \mathrm{C}$ for $3 \mathrm{~min}$. Curcumin concentration was assayed spectrophotometrically at $425 \mathrm{~nm} . \%$ EE was determined as follows:

$\%$ Entrapment $=$ (Amount of entrapped drug/Total Efficiency $=$ amount of drug $) \times 100$

\section{In vitro Release Testing}

In vitro release behavior of the selected $\mathrm{SD} / \mathrm{P}$ was monitored using dialysis bag method with minor modifications. ${ }^{24}$ Specific amounts of the investigated SD/ $\mathrm{P}$ (equivalent to $1 \mathrm{mg}$ curcumin) were vortexed with $1.5 \mathrm{~mL}$ ethanolic phosphate buffer solution $(30 \% \mathrm{v} / \mathrm{v} ; \mathrm{pH}$ $7.4)$ then placed in dialysis cellulose bags. The bags were locked from both ends. Prior to this, the cellulose bags were soaked in distilled water overnight. Following, the filled bags were transferred individually to $90 \mathrm{~mL}$ glass bottles containing $50 \mathrm{~mL}$ of the release medium. The bottles were placed in a thermostatically controlled shaker (Unimax, IKA, Germany) at $100 \mathrm{rpm}$ and $37 \pm 0.2{ }^{\circ} \mathrm{C}$. Aliquots of $3 \mathrm{~mL}$ were withdrawn at predefined time intervals and analyzed for curcumin content spectrophotometrically at $425 \mathrm{~nm}$. The withdrawn aliquots were replaced with $3 \mathrm{~mL}$ of fresh release medium to ensure sink conditions are maintained. The release of curcumin hydroalcoholic solution was determined following the same steps for comparison purposes.

The \% curcumin released after 2 and $24 \mathrm{~h}(\mathrm{Q} 2 \mathrm{~h} \&$ Q24h, respectively) were determined to compare between the investigated formulations.

In addition, the \% release efficiency ( $\%$ RE) was calculated as the area under the release curve to the last time point designated as the rectangle's area percentage and signifying $100 \%$ release after corresponding time. ${ }^{25}$

$$
\mathrm{RE} \%=\int_{0}^{\mathrm{f}} \mathrm{y} \cdot \mathrm{dt} / \mathrm{y}_{100} \mathrm{tx} 100
$$

where the integral is the area under the release curve to time $\mathrm{t}$ and $\mathrm{y}_{100}$ is the area of the rectangle described by $100 \%$ release at time $t$.

\section{Aerodynamic Particle Size Characterization}

Certain amounts of the improved formulations ( $\mathrm{SD} / \mathrm{P} 4$ and $\mathrm{SD} / \mathrm{P} 6$ ) and pure curcumin powder equivalent to $500 \mu \mathrm{g}$ drug were placed separately in hard gelatin capsules (size 3) suitable for the Aerolizer ${ }^{\circledR}$ dry powder inhaler (DPI) (Novartis Pharma, Egypt) to determine their aerodynamic characters using Andersen MKII Cascade Impactor (ACI; GF 50, Copley Scientific Ltd, UK).

All the parts of the ACI (including the pre-separator) were washed in the mobile phase mixture composed of acetonitrile: methanol: water at a ratio of 40:20:40 (\% v/v/ v) and adjusted at $\mathrm{pH} 3.0$ then left to dry. Silicone fluid (Releasil B silicone spray, Dow Corning Limited, Barry, Glamorgan, UK) was used to spray the collection plates. After which, they were left to dry for at least one hour before analysis. The ACI was modified by replacing stages 0 and 7 by -0 and -1 in order to achieve a flow of $60 \mathrm{~L} /$ min. $^{26-29}$ Additionally, the $10 \mathrm{~mL}$ of the mobile phase mixture was placed in the pre-separator; and the final filter was a GF 50 (Copley Scientific Ltd, UK).

The inhalation flow through the mouthpiece of the Aerolizer $^{\circledR}$ DPI was adjusted at $60 \mathrm{~L} / \mathrm{min}$ for a duration of $4 \mathrm{~s}$. Under such modification, an inhaled air volume of 4 L was drawn through the inhaler. ${ }^{30,31}$ The flow was measured by an electronic digital flow meter (MKS Instruments, USA). To avoid any leakage, Parafilm M laboratory film (Pechiney Plastic Packaging, USA) was utilized for sealing the ACI.

Three determinations were made for each formulation, according to a randomization procedure. Groups of three doses (1500 $\mu \mathrm{g}$ curcumin) were selected randomly using random schedules for each aerodynamic size determination. Each dose of three capsules was separately placed in the Aerolizer ${ }^{\circledR}$ DPI and discharged into the ACI apparatus. Following the patient information leaflet instructions, the inhaler was loaded with one capsule to deliver one dose. It was placed tightly into the ACI USP throat and aligned along the horizontal axis. To allow such a volume of $4 \mathrm{~L}$ of air to be withdrawn each time, as recommended in Pharmacopeial Methods, the pump (with adjusted parameters as mentioned) was switched on for $4 \mathrm{~s}^{30,31}$ For each determination, three doses were discharged into the ACI. Each stage of the ACI was rinsed with a specified volume of the mobile phase mixture and the filter of the last stage (final filter) was completely submerged in the mobile phase mixture and then sonicated for $3 \mathrm{~min}$ (preliminary analysis revealed that this procedure removes all drug entrained on the filter). The amount of drug deposited on each stage and the final filter were determined by a previously validated high-performance liquid chromatography (HPLC) method. ${ }^{32}$ The conducted HPLC method used Chromosil C18 analytical column (Water Associates, $250 \mathrm{~mm} \times 4.6 \mathrm{~mm}, 5 \mu \mathrm{m}$, HPLC Bonda Pak. $10 \mu \mathrm{m}$, USA) and an isocratic pump (LC-10 AS, Shimadzu, Japan). 
A volume of $100 \mu \mathrm{L}$ of sample was injected at ambient temperature for $10 \mathrm{~min}$ runtime with a flow of $1 \mathrm{~mL} / \mathrm{min}$ and effluents were identified at $370 \mathrm{~nm}$ with a UV detector (RF-551, Shimadzu, Japan). The sample retention time was $6 \mathrm{~min}$. The limit of detection was $0.305 \mu \mathrm{g} / \mathrm{mL}$ and the lower limit of quantification was $2 \mu \mathrm{g} / \mathrm{mL}$. The mobile phase was a mixture of acetonitrile: methanol: water $(40: 20: 40 \mathrm{v} / \mathrm{v} / \mathrm{v})$ and the $\mathrm{pH}$ was adjusted at 3 .

\section{Aerodynamic Data Analysis}

The aerosolization efficiency was assessed by calculating different parameters. Total emitted dose (TED; the \% of the drug amount that reached the ACI relative to the nominal dose), fine particle dose (FPD, particles less than $5 \mu \mathrm{m}$ ), fine particle fraction (FPF; the $\%$ of fine particles in the delivered dose) as well as the mass median aerodynamic diameter (MMAD; the diameter at the midpoint on the frequency distribution) which was measured using Copley Inhaler Testing Data Analysis Software (CITDAS, Copley Scientific, Nottingham, UK).

\section{Fourier Transform Infrared Spectroscopy (FT-IR)}

FT-IR spectra were recorded for the selected formulations, the physical mixtures as well as their individual components. Two milligrams of each sample was first mixed with dry potassium bromide then the mixture was pressurized into a disc and scanned over a range of wavelength from 4000 to $400 \mathrm{~cm}^{-1}$ using FT-IR 8400 (Shimadzu, Kyoto, Japan).

\section{Differential Scanning Calorimetry (DSC)}

DSC analysis was assessed by accurately weighing $2 \mathrm{mg}$ from the investigated formulation as well as its components individually in a hermetically sealed aluminum pan, then heated up from 25 to $350{ }^{\circ} \mathrm{C}$ at a constant rate of $10{ }^{\circ} \mathrm{C} / \mathrm{min}$ under nitrogen atmosphere. All scans were analyzed using Shimadzu differential scanning calorimeter (DSC-50, Shimadzu, Japan).

\section{Transmission Electron Microscope (TEM)}

Transmission electron microscopy (TEM) was used to study the morphology of the formed liposomes. Briefly, proliposomes were hydrated with drops of phosphate buffer $(\mathrm{pH} 7.4)$ then vortexed for 2 min. A drop of the dispersion was fixed onto copper grid and stained with $2 \%$ phosphotungstic acid then air-dried. The stained samples were examined using TEM (JEM-1230, Jeol, Tokyo, Japan) at $70 \mathrm{kV}$.

\section{Scanning Electron Microscopy (SEM)}

The surface morphology of the selected SD/P was imaged using a scanning electron microscope (SEM; JSM-6400; JEOL Ltd., Tokyo, Japan) at a voltage of $20 \mathrm{kV}$. Samples were fixed on stubs using double-sided adhesive tape, then sputter-coated with a thin layer of gold.

\section{Gamma Sterilization}

The chosen pre-packed formulations (in containers with dry ice) were irradiated with $10 \mathrm{KGy}$ using a gamma irradiator (Gamma cell 1000; BEST Theratronics, Ontario, Canada). ${ }^{33,34}$ The sterilized samples were re-evaluated for their $\mathrm{PS}, \mathrm{EE} \%$ and in vitro release behavior.

The similarity factor $\left(f_{2}\right)$ was calculated to detect the similarity between the irradiated and non-irradiated formulations as follows: ${ }^{35}$

$$
\mathrm{f}_{2}=50 \cdot \log \left[\left\{1+\left(\frac{1}{\mathrm{n}}\right) \sum \mathrm{t} \stackrel{\mathrm{n}}{=} 1\left(\mathrm{R}_{\mathrm{t}}-\mathrm{T}_{\mathrm{t}}\right)^{2}\right\}^{-0.5} .100\right]
$$

where $\mathrm{n}$ is the sampling number, $\mathrm{R}$ and $\mathrm{T}$ are $\%$ drug released prior and post sterilization at each time point $\mathrm{t}$.

\section{Cell Line Studies A549 Cell Line Propagation}

Human epithelial cell line (A549), from a lung carcinoma tissue was purchased from the American Type Culture Collection (ATCC), Rockville, MD, USA.

A549 cells were cultured in RPMI-1640 medium. Both inactivated fetal calf serum (10\%) and gentamycin $(50 \mu \mathrm{g} /$ $\mathrm{mL}$ ) were added to the medium. Cells were maintained in a suitable environment at $37^{\circ} \mathrm{C}$, humidified atmosphere with $5 \% \mathrm{CO}_{2}$ and were regularly sub-cultured.

\section{Cytotoxicity Evaluation Using MTT Test}

Cellular uptake of curcumin, improved formulations (SD/ P4 and SD/P6) and their corresponding non-medicated ones was studied using the human propagated tumor A549 cell line. A549 cell lines were suspended in RPMI-1960 medium then incubated for three days so that a concentration of $5 \times 10^{4}$ cell/well in Corning ${ }^{\circledR} 96$ well culture plates was reached. To the well plates, equivalent amounts of tested samples were added $(n=3)$. Eight concentrations for each tested sample were used. Furthermore, control groups were run for each well plate $(n=3)$. Incubation was carried for 
24 h. MTT (3-(4,5-dimethylthiazol-2-yl)-2,5-diphenyltetrazolium bromide) assay was used to assess the viability of the cells. ${ }^{36}$ The old media was exchanged with fresh RPMI-1640 medium $(100 \mu \mathrm{L})$ without the addition of phenol red. Following, $10 \mu \mathrm{L}$ of $12 \mathrm{mM}$ MTT reagent was added to all wells plates then incubated for $4 \mathrm{~h}$ at $37^{\circ}$ $\mathrm{C}$ and $5 \% \mathrm{CO}_{2}$. At the end of incubation, $50 \mu \mathrm{L}$ DMSO was added and thoroughly mixed in every well then incubated for $10 \mathrm{~min}$ at $37^{\circ} \mathrm{C}$. Viable cells were quantified by measuring the optical density of $590 \mathrm{~nm}$ using a microplate reader (BIORAD, Hercules, CA, USA). The percentage viability was calculated according to the following formula:

$$
\% \text { Viability }=\left(1-\frac{\mathrm{ODt}}{\mathrm{ODc}}\right) \times 100
$$

where ODt and ODc are the average optical density of the tested wells filled with the tested samples and the non-treated cells, correspondingly. The $\%$ viability was illustrated against the investigated samples' concentrations to detect the influence of concentration on the viability of cells.

\section{Influence of the Selected SD/P on Pro-Inflammatory Cytokines Sample Preparation}

A549 cells were prepared in a concentration of $5 \times 10^{4}$ cell/ well. Fresh RPMI-1640 medium was added to each well. Tested samples (pure curcumin, improved SD/P4 and SD/P6) were added in concentrations equivalent to their corresponding $\mathrm{IC}_{50}$. Control groups were carried out for each well plate $(n=3)$. The well plate was incubated at $37^{\circ} \mathrm{C}$ for $4 \mathrm{~h}$ with $5 \%$ $\mathrm{CO}_{2}$. The obtained suspension underwent sonication using ultrasonic cell disruptor (Bioruptor ${ }^{\circledR}$ II, Cosmo Bio, Japan) followed by centrifugation (HERMLE Labortechnik GmbH, Germany) for $30 \mathrm{~min}$ at $1500 \times \mathrm{g}$. Finally, the supernatant was analyzed for its content of TNF- $\alpha$, IL- 6 and IL- 10 .

\section{Capture of Tumor Necrosis Factor-Alpha (TNF- $\alpha$ )}

The technique used is similar to the one proposed by De Groote et al as a one-step culture-immunoassay procedure. ${ }^{37}$ Antihuman TNF- $\alpha$-coated sterile microplates were prepared for the incubation of tested samples or 100 $\mu \mathrm{L}$ of TNF- $\alpha$ standards $(5 \mathrm{ng} / \mathrm{mL})$ in $900 \mu \mathrm{L}$ assay buffer at $20-23^{\circ} \mathrm{C}$ for $10 \mathrm{~min}$. After complete dissolution, plates were capped and re-incubated for another $2 \mathrm{~h}$ under similar conditions to allow TNF- $\alpha$ production and immunocapture. Later, the caps were removed, and the plates were extensively washed to ensure complete removal of the unbound substrates. An antihuman TNF- $\alpha$ conjugate, a streptavidin-horseradish peroxidase (HRP), was added to each well to capture the produced TNF- $\alpha$. The plates were then incubated at room temperature for 30 $\mathrm{h}$ with continuous shaking. Extensive washing was carried again and $100 \mu \mathrm{L}$ of TMP (tetramethylbenzidine; a chromogen solution) was added to each well and incubated for additional 15 min under unchanged conditions of shaking and temperature. The added TMP allowed for a colorimetric reaction to take place where the color intensity is proportional to the TNF- $\alpha$ produced. Stop solution $(200 \mu \mathrm{L})$ was added to the plates then the absorbance readings at $450 \mathrm{~nm}$ for each well were measured using a microplate reader. The concentration of the produced TNF- $\alpha$ could be measured from the standard curve.

\section{Detection of IL- 6 and IL- 10 by Enzyme-Linked Immunosorbent Assay}

ELISA (Enzyme-linked Immunosorbent Assay) was used to detect the levels of the produced IL-6 and IL-10 in a method similar to that utilized by De Groote. ${ }^{38}$ Assay buffer was added in volumes of $100 \mu \mathrm{L}$ to each well of a microwell plate. Dilutions of the kit standard were added serially to each plate. After that, $100 \mu \mathrm{L}$ of the tested formulations as well as the blanks was added to the wells. The produced interleukins were captured using streptavidin-HRP enzyme linked to biotin (specific detector for IL-6 and IL-10). Incubation of the microwell plate was carried out for $1 \mathrm{~h}$ at a temperature of $20-23^{\circ} \mathrm{C}$. After incubation, wells were washed to remove unbound substrates then TMB solution was added to each well to produce color with the bound biotinylated streptavidinHRP. The intensity of the color produced, measured by the microplate reader at $450 \mathrm{~nm}$ wavelength, is proportional to the concentration of IL- 6 and IL-10 present in the sample. Unknown concentrations of interleukins could be easily figured out from the standard curve.

\section{Lung Pharmacokinetic Studies Study Design}

Seventy-two male Albino rats, weighing 220-260 g, were used for our study. The rats were housed in a pathogenfree animal house and had free access to food and water. They were left to get accustomed to the environment for a week prior to the experiment. The study itself followed 
a simple parallel design in which 24 rats were randomly allocated in three treatment groups (pure drug, SD/P4 and $\mathrm{SD} / \mathrm{P} 6$ groups). The study protocol was approved by the institutional review board of the Research Ethics Committee of the Faculty of Pharmacy, Cairo University, Egypt and (PI; 2648) and was in accordance with the Guide for the Care and Use of Laboratory Animals of the National Institutes of Health (NIH publication No. 85-23, 1996).

\section{Dose Administration}

A weight from each of the investigated samples equivalent to $1 \mathrm{mg}$ curcumin ${ }^{39}$ was administered intratracheally using a $10 \mathrm{~mL}$ syringe and an in-house endotracheal hollow stainless-steel tube $\left(120^{\circ}\right.$ bend and $5 \mathrm{~cm}$ long) like that offered by Penn-Century, Model DP-EXT-R. The tracheal intubation technique was carried out as previously discussed. ${ }^{40,41}$ Prior to the intubation, the rats were anesthetized intra-peritoneally using thiopental $(50 \mathrm{mg} /$ $\mathrm{kg}$ ) which was safe and enough to perform the experiment. The 1st group received pre-sterilized curcumin powder (curcumin mixed with $\mathrm{HP} \beta C D$ ) as a control. The 2nd and 3rd groups received the improved formulations $\mathrm{SD} /$ $\mathrm{P} 4$ and SD/P6, respectively. The investigated samples were pre-transferred to the syringe individually. Following, the mouths of the anesthetized rats were opened using a sterile forceps and the passage of the endotracheal tube was monitored using an endoscope equipped with a camera (Warmhoming, China). The endotracheal tube was placed in trachea through mouth, and the total loaded dose in the syringe was administered by just one puff.

\section{Sample Collection}

At definite time intervals $(0.5,1,2,4,6$ and $24 \mathrm{~h}), 4$ rats from each group were sacrificed by thiopental injection overdose. The lungs of the sacrificed animal were removed, weighed and homogenized (Heidolph Instruments, Germany) at $5000 \mathrm{rpm}$ by adding $2 \mathrm{~mL}$ saline. The homogenate was stored at $-80^{\circ}$ prior to assay.

The whole procedure is presented in Figure 1.

\section{Chromatographic Conditions}

The lung tissue samples were analyzed for curcumin content using liquid chromatography (Shimadzu, Kyoto, Japan) coupled with triple quadrupole mass spectrometer (MS) [API 4000, AB Sciex Instruments, Framingham, MA, USA]. The internal standard was torsemide $(1 \mu \mathrm{g} / \mathrm{mL})$. The mobile phase was composed of $55 \%$ acetonitrile, $45 \%$ water and $0.1 \%$ formic acid. Samples were extracted with $4 \mathrm{~mL}$ tertiary butyl methyl ether, vortexed then centrifuged, supernatant was
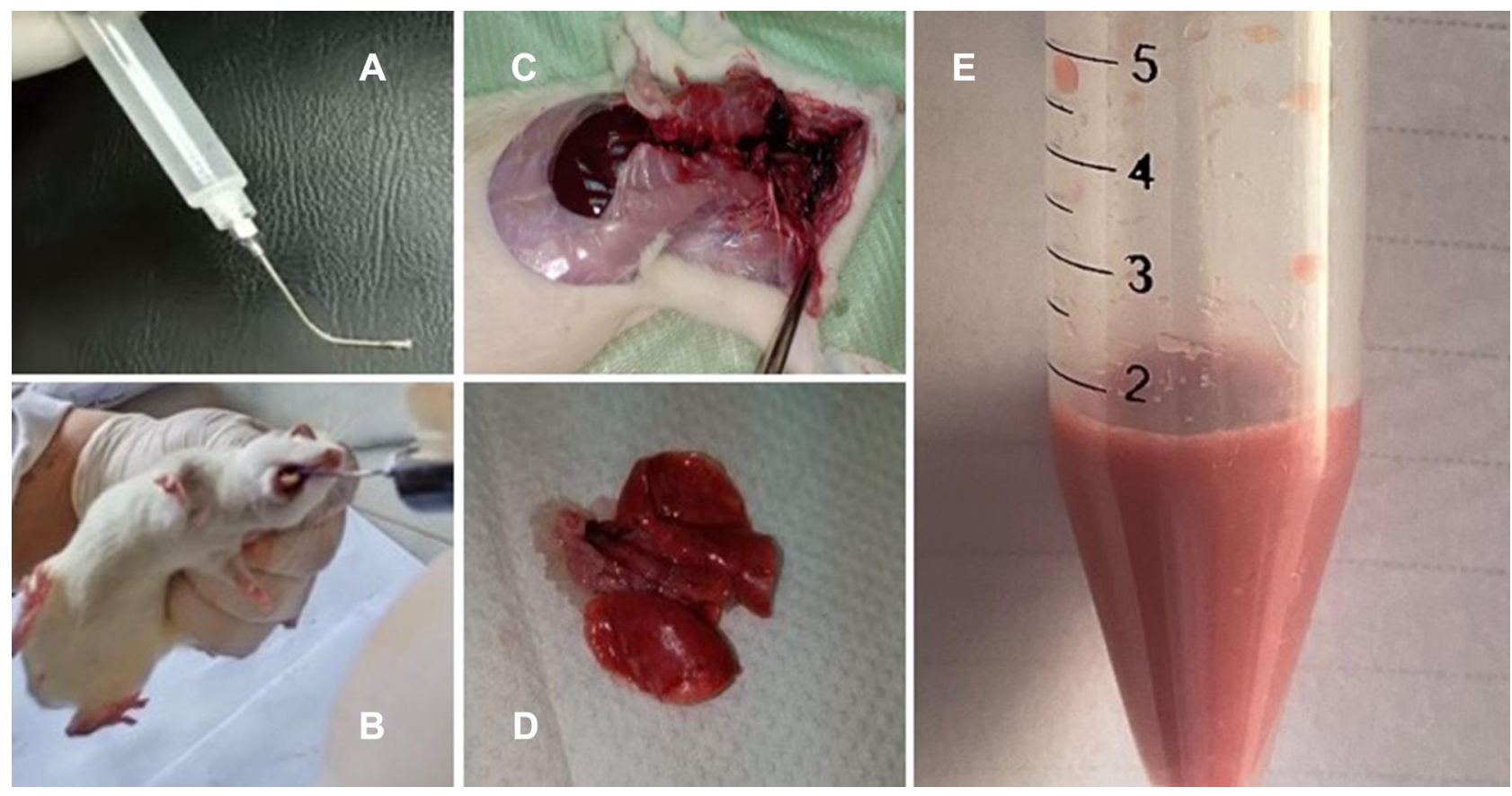

Figure I Steps of the surgical procedure of curcumin administration to a male Albino rat. (A) Syringe is prepared then (B) Endotracheal intubation of SD/P formulation (or free curcumin) in the rat. (C) At predefined time intervals, a rat is sacrificed and (D) lung tissue is isolated. (E) Later, prior to analysis, lung tissue is homogenized. 
assayed. Injection volume was $15 \mu \mathrm{L}$ and the elution process was isocratic and carried at a flow rate of $1 \mathrm{~mL} /$ min. The separation was carried on a $5 \mu \mathrm{m}, 4.6 \mathrm{~mm}$ x $50 \mathrm{~mm}$ Sunfire $^{\circledR}$ column (Waters corporation, Wilmslow, UK). All samples were assayed by MS/MS operated in multiple reaction monitoring mode and positive polarity at $5200 \mathrm{~V}$, using turbo spray ion source at $500^{\circ} \mathrm{C}$ probe temperature.

The pharmacokinetic parameters of curcumin like $\mathrm{C}_{\max }, \mathrm{T}_{\max }, \mathrm{AUC}_{(0-24)}, \mathrm{AUC}_{\text {inf }}$ and MRT were assessed by non-compartmental pharmacokinetic models using WinNonLin $^{\circledR} \quad$ version 5.3 software (Pharsight Corporation, Mountain View, CA).

\section{Data Analysis}

Statistical analyses were done using SPSS $^{\circledR}$ software (SPSS Inc., 23.00 IBM Corporation, NY, USA). Oneway analysis of variance (ANOVA) was used to test for significance with $\mathrm{P}$ values $<0.05$ considered significant. Least significant difference (LSD) correction was applied to detect significance between groups. Measurements were obtained from two different batches as well means and standard deviations were calculated from duplicate results $(n=4)$.

\section{Results and Discussion}

Different curcumin-loaded proliposomal formulations were prepared to study the effects of variable factors such as lecithin:cholesterol ratio, effect of SA and PLX 188 addition as well as the amount of carrier (HP $\beta C D)$ on the characterization parameters. Proliposomes can be prepared without the addition of carrier system; ${ }^{11}$ however, the obtained powder in this study was found to be sticky and could not be efficiently collected from the nano spray dryer, so a carrier was added. Cyclodextrins, among different carriers, are used for their roles as solubilizing and stabilizing agents through inclusion complex formation. ${ }^{42} \mathrm{HP} \beta \mathrm{CD}$ in particular is known to be more effective in enhancing both solubility and stability of curcumin among different cyclodextrins. ${ }^{43}$ In addition, the anti-angiogenic effect of curcumin is vastly improved in presence of $\mathrm{HP} \beta C D .{ }^{43}$ This should limit blood, and consequently nutrient, supply to tumor cells leading to their eventual demise. A noticeable finding reported by Dufour et al suggested that $\mathrm{HP} \beta C D$ resulted in increased fine particle fraction (FPF) and reduced pulmonary leakage of budesonide compared to lactosebased formulation. ${ }^{44}$

\section{Characterization of the Prepared Spray-Dried Curcumin-Loaded Proliposomes (SD/P) Determination of Percentage Yield}

The obtained percentage yield values are presented in Table 1 . In general, the yield ranged from $52.75 \pm 0.03$ to $81.87 \pm 0.11 \%$. Such values are considered satisfactory as previously stated. ${ }^{36}$ These results suggested that the used preparation technique, in addition to the processing factors, was reliable for preparing curcumin-loaded SD/P.

\section{Particle Size (PS), Polydispersity Index (PDI) and Zeta Potential (ZP) Assay}

PS is considered a crucial factor affecting the fate of the particles after pulmonary administration. ${ }^{45}$ More specifically, formulations with particle size ranging between 100 and $200 \mathrm{~nm}$ were proven more effective for lung administration and imposed fewer systemic side effects. ${ }^{46}$ Furthermore, particles smaller than $200 \mathrm{~nm}$ can avert detection by alveolar macrophages and thus avoid rapid clearance. ${ }^{47}$ By referring to Table 1 , it is evident that formulations SD/P1, SD/P3, SD/P9, SD/P11, SD/P17 and $\mathrm{SD} / \mathrm{P} 19$ prepared using lower amounts of the carrier $(0.5$ g) produced significantly $(\mathrm{P}<0.05)$ larger $\mathrm{PS}$ values $>600$ $\mathrm{nm}$ compared to their counterparts prepared using larger amounts of the carrier $(1 \mathrm{~g})$. This might be attributed to the increased particle aggregation and hence poor powder flowability with lower carrier amounts, ${ }^{48,49}$ highlighting the importance of the added carrier.

By comparing the PS values of the formulations prepared using larger carrier amounts, it could be observed that they ranged between 160 and $365 \mathrm{~nm}$ which is well in line with what is acceptable for inhalation nanomedicine. ${ }^{50}$ Regarding lecithin:cholesterol ratio effect, it was evident that a significant $(\mathrm{P}<0.05)$ fall in PS occurred on decreasing lecithin:cholesterol ratio (SD/P2 $<\mathrm{SD} / \mathrm{P} 10<\mathrm{SD} / \mathrm{P} 18)$. These results indicated the prominent effect of decreasing lecithin concentration over increasing cholesterol concentration on the PS. Increasing cholesterol concentration might lead to an increase in PS. ${ }^{51,52}$ Increasing cholesterol incorporated into the lipid bilayer might have interfered with its closed packing which might have led to enhanced aqueous distribution within the vesicle resulting in an increase in PS. ${ }^{53}$ On the other hand, decreasing lecithin concentration causes a fall in PS which might be attributed 
to the decreased lipid content. ${ }^{54}$ Since lecithin is the main vesicle forming material while cholesterol is only incorporated into the walls of an already formed vesicle, this might suggest why lecithin effect was more prominent and an overall fall in PS was noticed on decreasing lecithin:cholesterol ratios. Additionally, the inclusion of SA as a positive charge inducer resulted in reduced PS values across different lecithin:cholesterol ratios. Formulations SD/P4, SD/P12 and SD/P20 showed significantly smaller PS values $(\mathrm{P}<0.05)$ than SA-free counterparts, suggestive that the inclusion of a surface charge inducer increased the surface free energy, which induced the formed particles to curve upon itself in order to gain some stability and reduce surface energy. In addition, similarly charged particles tend to move further away from each other due to repulsive forces. This reduced the tendency to aggregate resulting in smaller PS. ${ }^{55}$ Similar results were reported by Pamunuwa et al. ${ }^{56}$ Contrasting findings reported by Carafa et al suggested that the inclusion of charge modifier led to increased PS due to repulsion forces introduced into the lecithin-composed bilayer resulting in enlarged aqueous central compartment and, hence, increased PS. ${ }^{57}$

Regarding the effect of PLX 188 addition, it was obvious that its addition produced larger PS values $(\mathrm{P}<$ 0.05) compared to their counterparts lacking its addition through the different lecithin:cholesterol ratios. Furthermore, increasing PLX 188 amount from 6 to $10 \mathrm{mg}$ caused further increase in PS $(\mathrm{P}<0.05)$. This might be brought by the high HLB value of PLX 188 (> 24) which favors settling in the aqueous core causing the increased PS. ${ }^{51,58}$ It could be noticed that the PS lowering effect of SA was kept after its addition to PLX 188-based formulations $(\mathrm{P}<0.05)$.

PDI values $<0.5$ indicate that samples have a narrow and acceptable particle size distribution. ${ }^{59,60}$ This holds true for all formulations prepared where the obtained PDI values ranged between $0.247 \pm 0.04$ and $0.474 \pm$ 0.04 except the ones with lower amounts of HP $\beta C D$ (PDI $>0.5$ ) that might be due to increased particle aggregation which in turn might affect the stability of the formed particles.

ZP is a very useful analytical method for the determination of surface charge and hence physical stability of nanoparticles colloidal solution. ${ }^{61}$ All the prepared formulations lacking SA showed negative ZP values imposed by the ionized phosphate groups of lecithin. ${ }^{56}$ The obtained $\mathrm{ZP}$ values ranged from $-25.50 \pm 2.26$ to $-38.90 \pm 0.85$
$\mathrm{mV}$. On the other hand, the addition of SA imparted a positive charge which was attributed to the protonation of the basic $-\mathrm{NH}_{2}$ groups ${ }^{62}$ where $\mathrm{ZP}$ values ranged from $2.04 \pm 0.4$ to $39.70 \pm 2.12$. $\mathrm{ZP}$ values lying around \pm 30 are favorable, since the prepared particles are considered stable owing to the electric repulsion and hence avoiding possible flocculation and particle aggregation. ${ }^{63,64}$

From the results of PS measurements, it could be concluded that formulations prepared using lecithin:cholesterol ratio 1:1 were the best regarding their PS values. Furthermore, formulations prepared using low carrier amounts were excluded from further testing for their larger PS and PDI values.

\section{Drug Content (DC), Drug Loading (DL) and Entrapment Efficiency (EE)}

As can be seen from Table 1, the \% DC values of the tested $\mathrm{SD} / \mathrm{P}$ were high and ranged from $85.05 \pm 1.91 \%$ to $106.63 \pm 0.70 \%$.

This indicated the suitability of the formulation factors used for the preparation of proliposomes. Having high DC values indicated the production of potent proliposomes capable of delivering large amounts of drug using small amounts of formulation.

$\%$ DL calculation was carried out on all formulations and the results were documented in Table 1. Looking at the results, \% DL values increased as lecithin:cholesterol ratio increased across all formulations. However, such increase was found to be statistically insignificant $(\mathrm{P}>0.05)$. In general, DL values ranged from $1.68 \pm 0.06$ to $2.22 \pm 0.83 \%$.

The tested liposomal formulations possessed high \% EE values (Table 1) ranging between $90.15 \pm 2.19 \%$ and $102.20 \pm 0.71 \%$. The rationale behind high $\%$ EE could be attributed to the fact that curcumin is extremely lipophilic, meaning it is easily entrapped within the membrane of the formed vesicles.

Although formulations based on higher lecithin:cholesterol ratios possessed high \% EE values, as a result of enhanced vesicle formation at high lecithin concentrations, ${ }^{54}$ however these formulations were excluded from further studies based on their PS results. Further investigations were carried out on formulations using lecithin:cholesterol ratio of 1:1.

\section{In vitro Release Testing}

Curcumin release curves from $\mathrm{SD} / \mathrm{P}(2,4,5,6,7$ and 8) are illustrated in Figure 2. The release profile of all the 


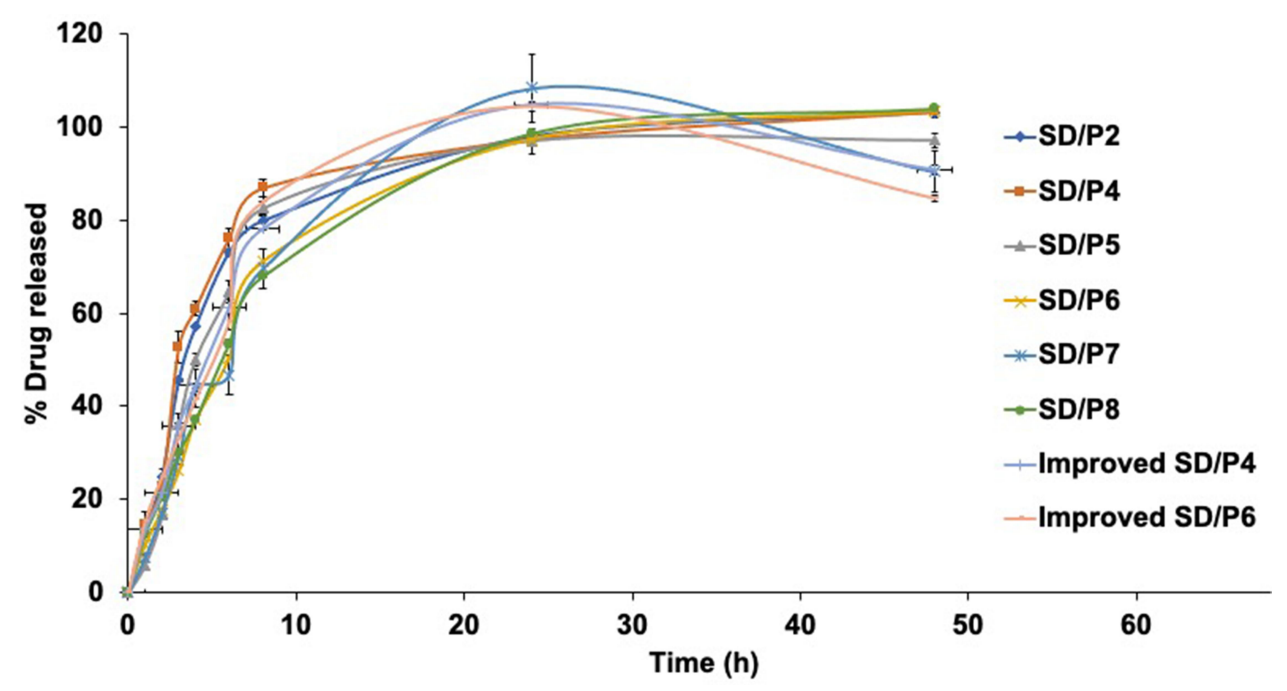

Figure 2 Curcumin release profiles from spray-dried proliposomes formulations (SD/P) in ethanolic phosphate buffer solution (30\% v/v; $\mathrm{pH} 7.4)$. The release profile of all the investigated formulations showed a distinctive biphasic release profile, where nearly more than $17.00 \%$ and less than $24.98 \%$ curcumin were released during the first 2 $\mathrm{h}$ followed by a sustained release pattern during the $48 \mathrm{~h}$ testing period. All formulations released more than $95 \%$ curcumin at Q24h. No significant difference could be detected between investigated formulations in either Q2h or Q24h $(P>0.05)$.

investigated formulations showed a distinctive biphasic release profile, where nearly more than $17.00 \%$ and less than $24.98 \%$ curcumin were released during the first 2 $\mathrm{h}$ followed by a sustained release pattern during the $48 \mathrm{~h}$ testing period. No significant difference could be detected between $\mathrm{Q} 2 \mathrm{~h}$ values of the investigated formulations $(\mathrm{P}>$ 0.05). The burst phase might be explained by the release of curcumin trapped near the surface layers of the vesicles giving imminent concentrations while curcumin trapped in the deep layers is slowly released by diffusion. ${ }^{65}$ Additionally, approximately $72.86 \pm 0.21 \%$ of curcumin was released from its hydroalcoholic solution within the first $3 \mathrm{~h}$, indicating the suitability of the used dialysis membrane for the drug and that any sustainment was related to the formulation.

By comparing the Q24h values, it could be observed that all the investigated formulations released more than $95 \%$ curcumin. The complete release of curcumin might be attributed to the inclusion of curcumin by $\mathrm{HP} \beta C D$ which provided protection against decomposition by external factors and improved solubility. ${ }^{66}$ In general, HP $\beta C D$ contains several hydroxyl groups at the surface imparting strong hydrophilicity while the core is strongly hydrophobic due to the shielding effect of the $\mathrm{CH}$ groups. ${ }^{66}$ Hydrophobic compounds, such as curcumin, are complexed in the hydrophobic core through Vander Waals, hydrophobic and hydrogen bond interactions. ${ }^{67,68}$ Additionally, all formulations possessed high \% RE values ranging from $79.67 \pm 7.86$ to $89.87 \pm 0.39 \%$.
From the obtained results, it is observed that no significant difference could be detected between all the tested formulations.

\section{Preparation and Characterization of the Improved Spray-Dried Curcumin-Loaded Proliposomes (SD/P)}

Based on the smallest PS values, formulations SD/P4 and SD/P6 were selected for further modifications. They were selected to study the effect of doubling the amount of carrier to $2 \mathrm{~g}$ and study its influence on the aerodynamic particle size aiming to prepare a formulation with improved pulmonary delivery.

The selected formulations (SD/P4 and SD/P6) were characterized after doubling $\mathrm{HP} \beta C D$ amounts (to $2 \mathrm{~g}$ ) while maintaining similar amounts of other components. The composition as well as characterization results of the improved formulations (improved SD/P4 and SD/P6) are displayed in Table 1. \% Yield values for the improved SD/ $\mathrm{P} 4$ and SD/P6 were comparable to their corresponding old ones. Increasing carrier amount led to significant PS reduction $(\mathrm{P}<0.05)$ similar to the results obtained before, where the obtained were $126.40 \pm 3.25$ and $150.65 \pm 4.31$ for the improved $\mathrm{SD} / \mathrm{P} 4$ and $\mathrm{SD} / \mathrm{P} 6$ versus $145.7 \pm 3.39$ and $164.15 \pm 6.86$ for the older SD/P4 and SD/P6, respectively. Again, this might be attributed to the improved flowability and further reduced particle aggregation. ${ }^{48,49}$ 
PDI values remained below 0.5 while ZP values of $31.90 \pm$ 1.697 and $31.20 \pm 3.11 \mathrm{mV}$ for the improved SD/P4 and $\mathrm{SD} / \mathrm{P} 6$, respectively, ensured physical stability of the proliposomes similar to their old counterparts. \% EE values were comparable with old formulations. $\% \mathrm{DL}$ of the improved SD/P4 and SD/P6 was significantly lowered compared to the old $\mathrm{SD} / \mathrm{P} 4$ and $\mathrm{SD} / \mathrm{P} 6$. This was expected due to the decreased ratio of drug: total solid weight. No significant difference was found $(\mathrm{P}<0.05)$ when the $\mathrm{Q} 2 \mathrm{~h}$ and Q24h were compared to their counterparts besides both formulations possessed high \%RE values of $86.36 \pm$ 0.27 and $85.50 \pm 0.21 \%$, respectively, suggesting that doubling carrier amount did not have any negative effect over release pattern. Release curves for the improved formulations can be seen in Figure 2.

\section{Aerodynamic Particle Size Characterization}

Assessment of the aerosolization efficiency allows determining the total emitted dose, the distribution of the drug at each stage as well as the aerodynamic particle size which predicts the fate of the inhaled particles in the lung. The results of the aerodynamic parameters are shown in Table 2. From the table, it could be observed that both the improved formulations SD/P4 \& SD/P6 resulted in significantly higher $\%$ TED $(p<0.001)$, FPD $(\mathrm{p}<0.001)$, FPF $(\mathrm{p}<0.001)$ and smaller MMAD $(\mathrm{p}<$ $0.01)$ compared to curcumin powder suggesting much better flow and hence efficient aerosolization and better lung deposition, especially with the improved SD/P4 formulation which showed more significance values $(\mathrm{p}<$ 0.05 ) compared to the improved SD/P6 formulation.

Furthermore, it was observed that the improved SD/P4 had significantly higher \% TED, FPF and FPD and significantly lower MMAD ( $<$ < 0.001) than improved SD/P6. The lower MMAD values of the improved SD/P4 (2.10 \pm $0.26 \mu \mathrm{m}$ ) might result in much better deep lung deposition at the bronchi or bronchial tubes if used by the patient. The accepted MMAD range was previously reported to be from 1 to $3 \mu \mathrm{m} .{ }^{69}$ This smaller MMAD of improved SD/
P4 compared to improved SD/P6 $(3.18 \pm 0.29 \mu \mathrm{m})$ might guarantee deposition in the alveolar region. ${ }^{70}$ It could be concluded that the use of curcumin-loaded proliposomes aerosol $^{71,72}$ might result in better lung deposition over the use of the pure powder suggestive for a future clinical bioequivalence test to consolidate this finding.

By comparing the results of the improved formulations (SD/P4 \& SD/P6) to their corresponding non-improved ones, it could be observed that they were significantly ( $\mathrm{P}$ $<0.05)$ superior regarding \% TED and FPD values. The \% TED values for the improved SD/P4 and SD/P6 compared to their corresponding non-improved ones were $98.40 \pm$ 1.49 and $79.96 \pm 1.85 \%$ versus $28.73 \pm 5.45$ and $46.70 \pm$ $3.60 \%$, respectively, while the calculated FPD values were $801.04 \pm 109.13$ and $350.51 \pm 99.81 \mu \mathrm{g}$ versus $229.74 \pm$ 9.71 and $208.57 \pm 76.88 \mu \mathrm{g}$, correspondingly. The obtained results indicated the importance of adjusting the used carrier amounts. Figure 3 confirms the superiority of the improved SD/P4 over the improved SD/P6, and the two improved formulations over curcumin in both the amounts, trapped within USP throat and pre-separator (Figure 3A) and reaching deeper in lung tissues (Figure 3B). The total amount of the improved SD/P4 trapped within both the pre-separator and USP throat was significantly lower than that of either the improved SD/P6 or the free curcumin $(\mathrm{P}<0.05)$. It is true that both the improved $\mathrm{SD} / \mathrm{P} 6$ and free curcumin reached until stage 4 in the Andersen cascade impactor, however, the amount of the improved SD/P6 was significantly larger $(\mathrm{P}<0.05)$. Only the improved SD/P4 managed to deposit much deeper in Andersen cascade impactor.

\section{Fourier Transform Infrared Spectroscopy (FT-IR)}

FT-IR spectroscopy is used to indicate possible interactions, if any, between two or more components in a formulation. FT-IR spectra are presented in Figure 4. The FT-IR spectrum of curcumin showed a stretching band at $3514 \mathrm{~cm}^{-1}$ due to phenolic $-\mathrm{OH}$ group. ${ }^{73}$ Other peaks at $1628 \mathrm{~cm}^{-1}$ and $1600 \mathrm{~cm}^{-1}$ are characteristic of $\mathrm{C}=\mathrm{O}$ and

Table 2 The Aerodynamic Characteristics of Curcumin Powder and Improved SD/P Formulations

\begin{tabular}{|l|c|c|c|}
\hline Measured Parameter & Curcumin Powder & Improved SD/P4 & Improved SD/P6 \\
\hline Total emitted dose (TED; \%) & $47.68 \pm 4.31$ & $98.40 \pm 1.49$ & $79.96 \pm 1.85$ \\
Fine particle dose (FPD; $\mu \mathrm{g})$ & $115.19 \pm 18.26$ & $801.04 \pm 109.13$ & $350.51 \pm 99.81$ \\
Fine Particle Fraction (FPF; \%) & $16.35 \pm 4.04$ & $54.35 \pm 8.22$ & $29.33 \pm 8.73$ \\
Mass median aerodynamic diameter (MMAD; $\mu \mathrm{m})$ & $3.81 \pm 1.15$ & $2.10 \pm 0.26$ & $3.18 \pm 0.29$ \\
\hline
\end{tabular}




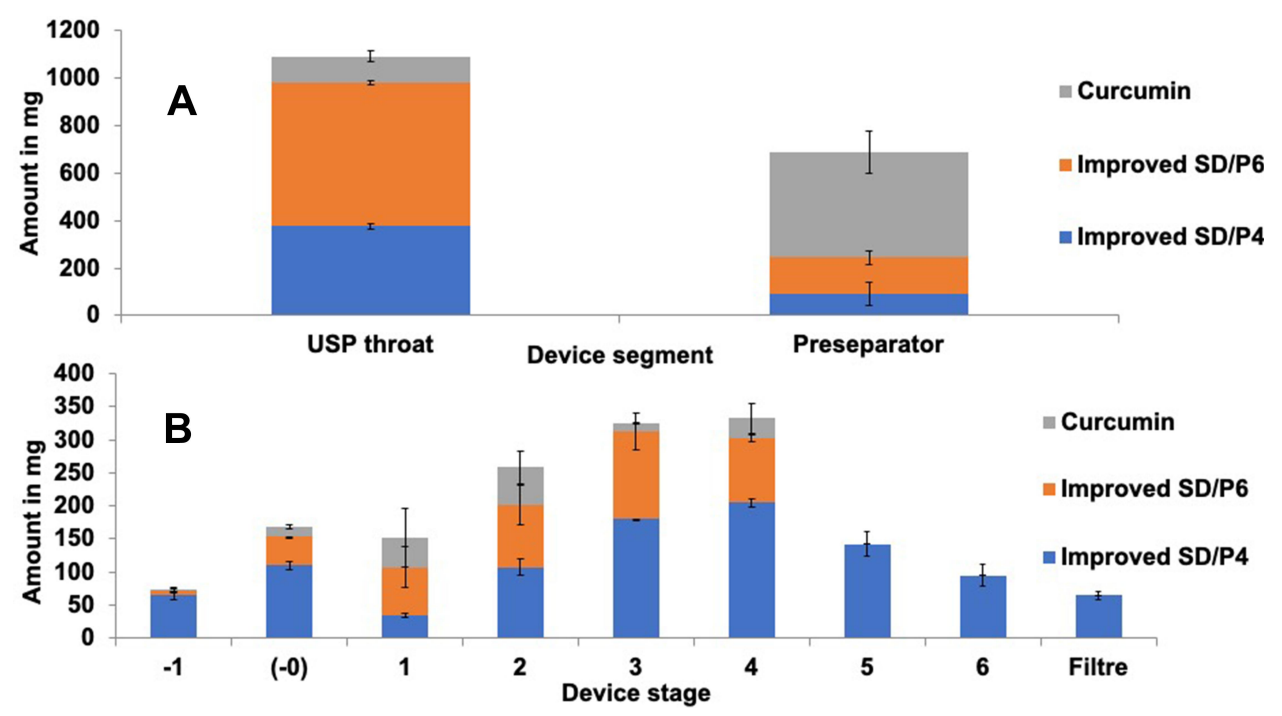

Figure 3 Curcumin amounts trapped (A) within the pre-separator and USP throat and (B) on each stage of the Andersen cascade impactor, respectively. The total amount of the improved SD/P4 trapped within both the pre-separator and USP throat was significantly lower than that of either the improved SD/P6 or the free curcumin (P < 0.05). The total amount of the improved SD/P4 reaching deeper stages of the Andersen cascade impactor was significantly higher than that of the improved SD/P6 (P $<0.05)$ with much superiority of the improved SD/P6 over free curcumin $(P<0.05)$.

$\mathrm{C}=\mathrm{C}$ stretching vibrations, respectively. Benzene ring $\mathrm{C}=\mathrm{C}$ showed characteristic vibrations at $1504 \mathrm{~cm}^{-1.74}$ In general, the FT-IR spectrum of curcumin is in line with what came in the literature. ${ }^{73,75}$ Lecithin FT-IR exhibits bands at $2924 \mathrm{~cm}^{-1}$ and $2854 \mathrm{~cm}^{-1}$ due to asymmetric $\mathrm{CH}_{2}$ and symmetric $\mathrm{CH}_{2}$ stretching vibrations, respectively, and scissoring vibrational band at $1465 \mathrm{~cm}^{-1.76}$ In cholesterol spectrum, a very distinguishable band is observed at $3406 \mathrm{~cm}^{-1}$ attributed to phenolic $\mathrm{OH}$ group while overlapping bands in the region $3000-2800 \mathrm{~cm}^{-1}$ are due to symmetric and asymmetric stretching vibrations of $\mathrm{CH}_{3}$ and $\mathrm{CH}_{2}{ }^{77}$ The FT-IR spectrum SA exhibited characteristic peaks at $2920 \mathrm{~cm}^{-1}$ (N-H stretching), $2850 \mathrm{~cm}^{-1}$ (C-H stretching) and $1570 \mathrm{~cm}^{-1}\left(\mathrm{NH}_{2}\right.$ bending) ${ }^{78}$ while that of PLX 188 is characterized by its principal peak at $2881 \mathrm{~cm}^{-1}$ due to aliphatic $\mathrm{C}-\mathrm{H}$ stretching. ${ }^{79}$ As for $\mathrm{HP} \beta C D$, the spectrum exhibited a distinguishable intense broad band at $3417 \mathrm{~cm}^{-1}$ due to $-\mathrm{OH}$ stretching vibration from intra- and intermolecular hydrogen bonding, at $2932 \mathrm{~cm}^{-1}$ for $\mathrm{CH}_{2}$ stretching vibration and at $1049 \mathrm{~cm}^{-1}$ due to $\mathrm{C}-\mathrm{O}-\mathrm{C}$ stretching vibration. ${ }^{73,75}$ All of the above peaks were present in the spectra of physical mixtures (PM4 \& PM6) and the improved formulations (SD/P4 \& $\mathrm{SD} / \mathrm{P} 6$ ). In both physical mixtures, curcumin peak was broadened and shifted to slightly lower wavelength (3441 $\mathrm{cm}^{-1}$ ) suggestive of slight hydrogen bond formation. However, in the spectra of the improved SD/P4 and 6 , the complete absence of curcumin peak along with other identifying peaks in the $1700-1500 \mathrm{~cm}^{-1}$ region, along with the shift of HP $\beta C D$ peaks to lower wavelength $\left(3398 \mathrm{~cm}^{-1}\right)$, might indicate possible formation of inclusion complex, ${ }^{80,81}$ possibly through hydrogen bond formation with $-\mathrm{OH}$ of curcumin.

\section{Differential Scanning Calorimetry (DSC)}

The DSC thermograms of the improved formulations (SD/ P4 and SD/P6), as well as their individual components and corresponding physical mixtures (PM4 and PM6), are presented in Figure 5. The DSC thermogram of curcumin showed a characteristic sharp endothermic peak at $158.1^{\circ} \mathrm{C}$ representing its melting behavior and indicative of its crystalline nature which is in line with the literature. ${ }^{82}$ Lecithin displayed a very broad endothermic peak at $330.9^{\circ} \mathrm{C}$ while cholesterol thermogram showed an endothermic peak at $144.7^{\circ} \mathrm{C}$ due to their respective melting. Thermogram of SA showed two endothermic peaks, one at $53.5^{\circ} \mathrm{C}$ possibly due to loss of water of crystallization, the second one at $103.1^{\circ} \mathrm{C}$ that implies its melting. PLX 188 thermogram displayed a very sharp endothermic peak at $56.7^{\circ} \mathrm{C}$ indicating its melting. $\mathrm{HP} \beta \mathrm{CD}$ possessed two endothermic peaks, one at $70.7^{\circ} \mathrm{C}$ due to dehydration and the other at $337.2^{\circ} \mathrm{C}$ due to fusion and decomposition.

The thermograms of the physical mixtures (PM4 \& PM6) of improved formulations showed disappearance of curcumin characteristic peak. Additionally, a marked shift 

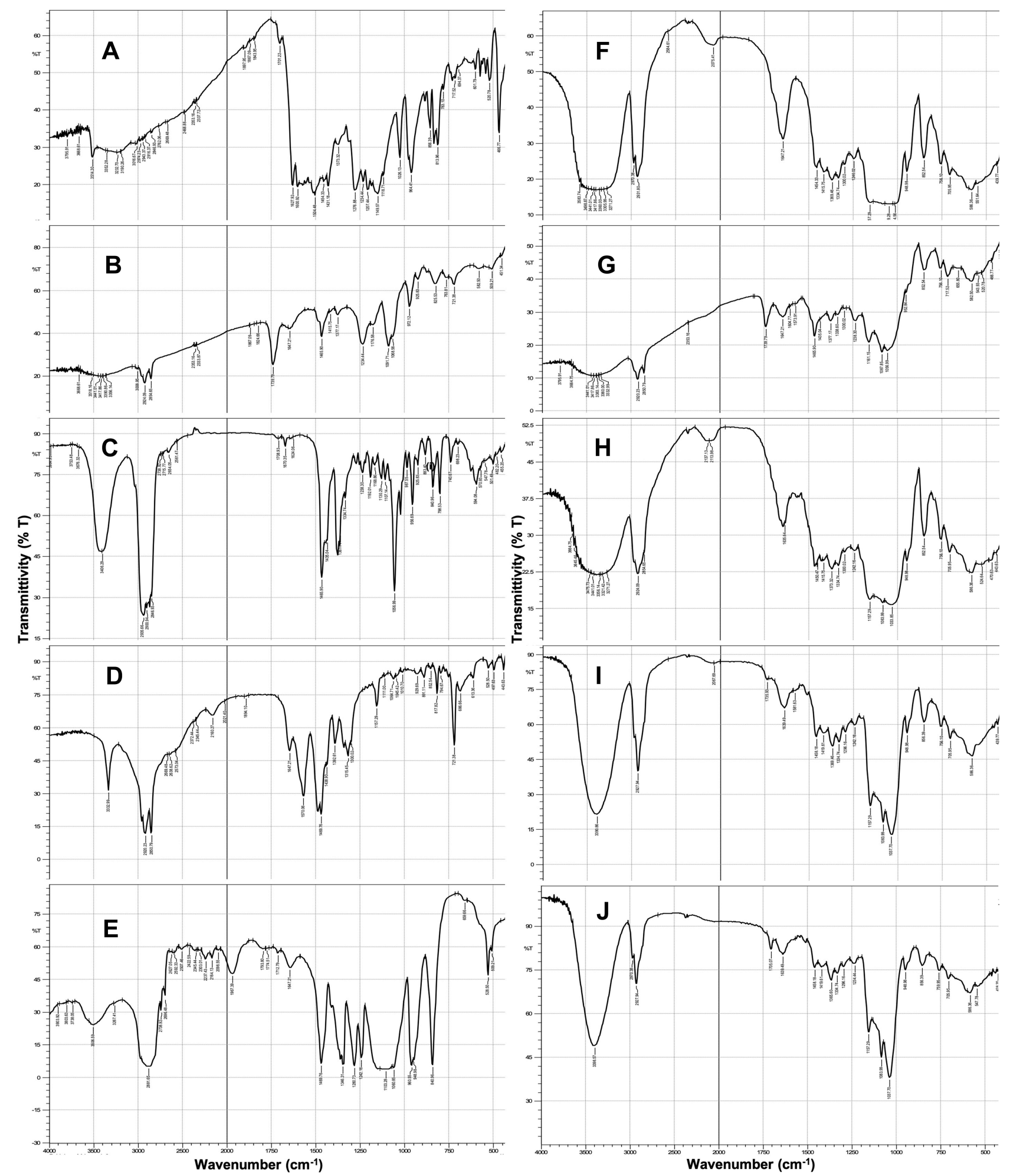

Figure 4 FT-IR spectra of (A) curcumin, (B) lecithin, (C) cholesterol, (D) SA, (E) PLX I88, (F) HPßCYD, (G) SD/P4 improved physical mixture, (H) SD/P6 improved physical mixture, (I) improved SD/P4 formulation and (J) improved SD/P6 formulation. The characteristic peak of curcumin completely disappeared in the spectra of the improved SD/P formulations with the shift of HP $\beta C D$ peak to a lower wavelength ( $\mathbf{I}$ and $\mathbf{J}$ ) are suggestive of possible formation of inclusion complex of curcumin in HP $\beta C D$.

in the melting peaks of $\mathrm{HP} \beta \mathrm{CD}$ to lower temperatures at $296.8^{\circ} \mathrm{C}$ and $294.4^{\circ} \mathrm{C}$ could be observed with the aforementioned physical mixtures, respectively, indicating lower melting point of HP $\beta C D$ in the physical mixtures. The endothermic peaks due to loss of bound water of $\mathrm{HP} \beta \mathrm{CD}$ could be observed at temperatures of $71.4^{\circ} \mathrm{C}$ and 


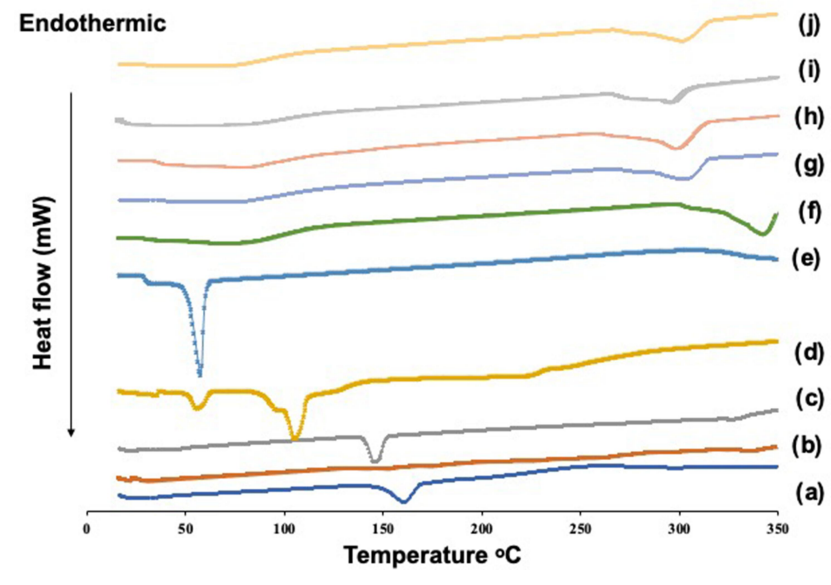

Figure 5 DSC thermograms of (a) curcumin, (b) lecithin, (c) cholesterol, (d) SA, (e) PLX 188, (f) HPßCYD, (g) SD/P4 improved physical mixture, (h) SD/P6 improved physical mixture, (i) improved SD/P4 formulation and (j) improved SD/P6 formulation. The characteristic endothermic peak of curcumin completely disappeared in the DSC thermograms of the improved SD/P formulations with the shift of the endothermic peak of HP $\beta C D$ to a lower temperature coupled with a decrease in its intensity, all of which is suggestive of possible interaction and complexation of curcumin in $\mathrm{HP} \beta C D$ ( $\mathrm{i}$ and $\mathrm{j})$.

$72.1^{\circ} \mathrm{C}$ with the afore-mentioned PMs, in respective order. The absence of curcumin characteristic peak in PMs could be attributed to the molecular dispersion of curcumin in its carrier with the formation of solid solution. This resulted in dilution of curcumin in the mixture and diminishing its characteristic peak. This was also reported by FernándezRomero et al. ${ }^{83}$ Both the improved $\mathrm{SD} / \mathrm{P} 4$ and $\mathrm{SD} / \mathrm{P} 6$ displayed very broad peaks at $280.1{ }^{\circ} \mathrm{C}$ and $293.6^{\circ} \mathrm{C}$, respectively, which were reminiscent of the endothermic peaks of $\mathrm{HP} \beta C D$, albeit with a shift to lower temperatures and very sharp decrease in intensity. The intensive reduction in dehydration peaks of $\mathrm{HP} \beta C D$ at $64.2^{\circ} \mathrm{C}$ and $65.1{ }^{\circ} \mathrm{C}$ might be endorsed to the elimination of water during spray

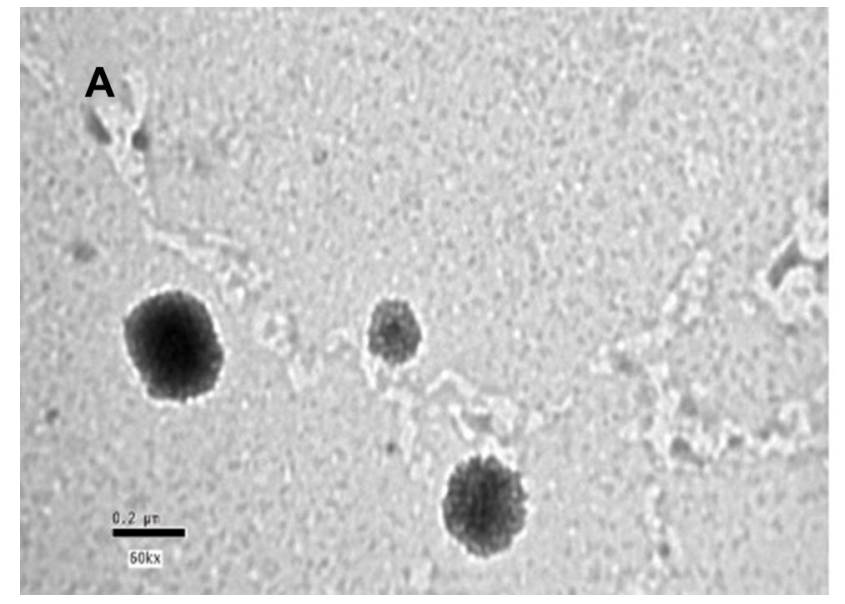

drying. Again, we can notice the absence of curcumin peak, which when considered together with the shift and intensive broadening of $\mathrm{HP} \beta \mathrm{CD}$ peak, further indicate the possible formation of inclusion complex. ${ }^{80,81}$

\section{Transmission Electron Microscope (TEM)}

The TEM micrographs (Figure 6) of the selected, reconstituted improved SD/P4 and SD/P6. Both images showed the formation of spherical liposomes.

\section{Scanning Electron Microscopy (SEM)}

Figure 7 shows the SEM images of the chosen formulations, improved SD/P4 and SD/P6. Overall, the images showed the formation of collapsed, hollow-shaped spherical particles, which might have occurred during sample preparation due to the increased pressure in the apparatus more than that in the particle. ${ }^{84}$

\section{Gamma Sterilization}

Both the sterilized improved SD/P4 \& SD/P6 did not show any significant difference with the non-sterilized counterparts in PS and \% EE ( $p>0.05)$. The PS and EE values for improved SD/P4 before and after sterilization were 420.30 \pm 40.16 versus $447.00 \pm 34.64 \mathrm{~nm}$ and $92.15 \pm 0.78$ versus $90.70 \pm 2.54 \%$, correspondingly. While those for improved $\mathrm{SD} / \mathrm{P} 6$ were $420.30 \pm 40.16$ versus $447.00 \pm 34.64 \mathrm{~nm}$ and $92.15 \pm 0.78$ versus $90.70 \pm 2.54 \%$, respectively.

The obtained release profiles of both formulations were nearly superimposing as indicated by $f_{2}$ value of 72.10 and 70.13 for improved SD/P4 and SD/P6, respectively. $\mathrm{f}_{2}$

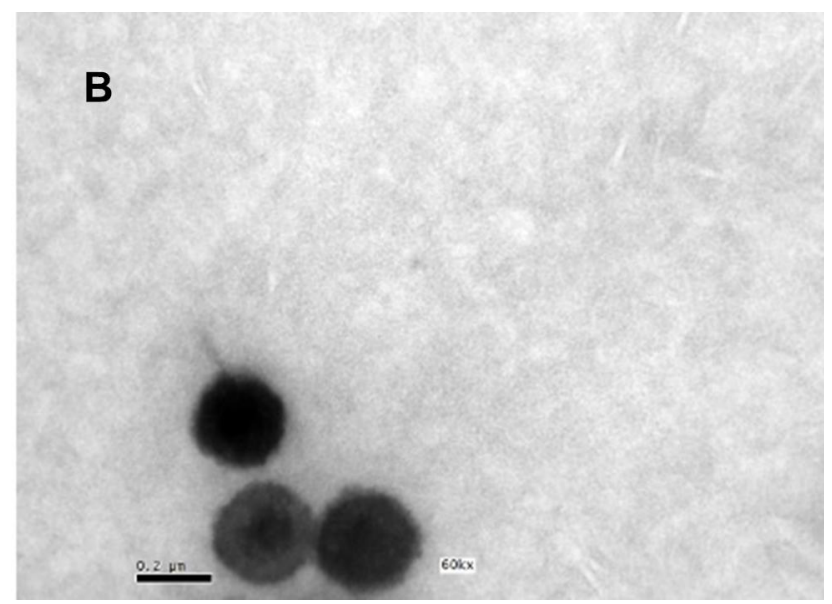

Figure 6 TEM images of the improved (A) SD/P4 and (B) SD/P6. Both formulations showed spherical liposomes. 

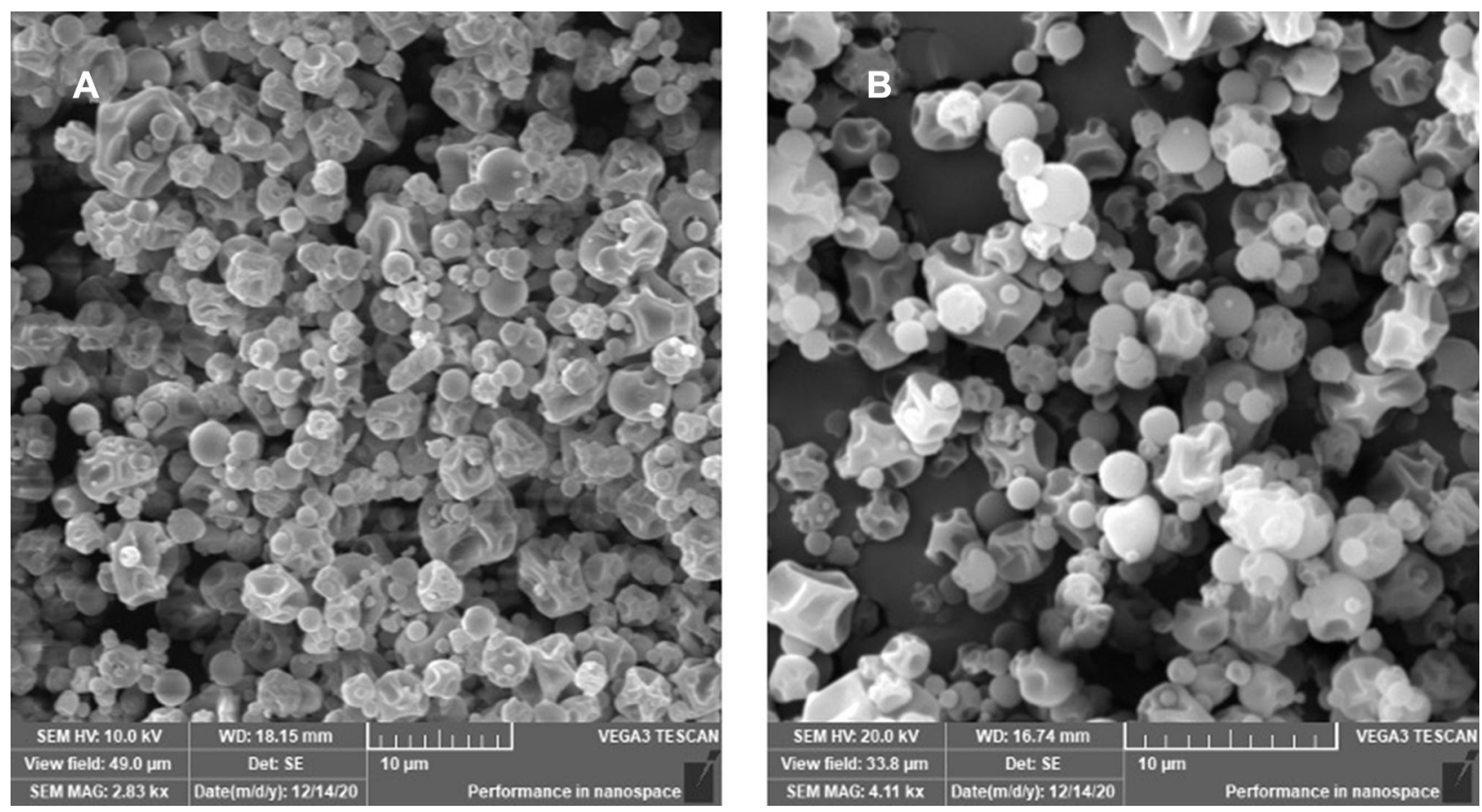

Figure 7 SEM images of the improved (A) SD/P4 and (B) SD/P6. Both formulations showed hollow-shaped spherical particles.

values between 51 and 100 signify similar release profiles. $^{35}$

\section{Cell Line Studies}

\section{Cytotoxicity Evaluation Using MTT Test}

The growth inhibitory effect of curcumin on lung tumor A549 cells was evaluated. From Figure 8A, it could be noticed that the tested samples inhibited the cell growth significantly $(\mathrm{p}<0.05)$ in comparison to the control. Also, it could be observed that the non-medicated improved formulations $\mathrm{SD} / \mathrm{P} 4$ and $\mathrm{SD} / \mathrm{P} 6$ possessed $\mathrm{IC}_{50}$ values 2.2 and 2-fold higher than the corresponding medicated improved formulations (59.36 and $63.33 \mu \mathrm{g} / \mathrm{mL}$ versus 26.48 and $30.97 \mu \mathrm{g} / \mathrm{mL}$ ), respectively. Additionally, curcumin showed comparable high $\mathrm{IC}_{50}$ values $(63.76 \mu \mathrm{g} /$ $\mathrm{mL}$ ) with the non-medicated formulations.

The growth inhibition produced by the non-medicated improved formulations (SD/P4 and SD/P6) could be attributed to the presence of SA in the phospholipid structure of the proliposomes. SA is thought to enhance the cell
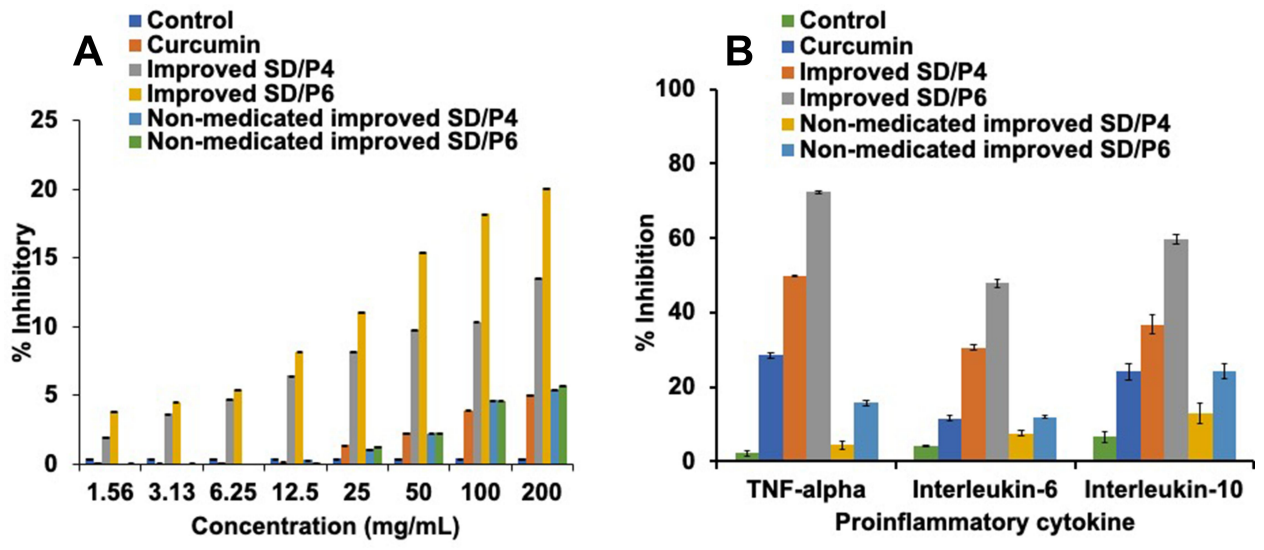

Figure 8 Effect of curcumin powder, medicated improved formulations and non-medicated improved formulations on (A) the growth of A549 tumor cells and (B) the levels of TNF- $\alpha$, IL-6 and IL- 10 as measured in A549 tumor cells. The growth inhibitory effect of the improved formulations was significantly higher (P < 0.05 ) than that of the free curcumin $(\mathbf{A})$. Also, the improved formulations were significantly more potent $(P<0.05)$ at lowering the levels of the pro-inflammatory cytokines as compared to the free curcumin (B). 
apoptosis through the expression of phosphatidylserine on the extracellular surface of most tumor cells. ${ }^{85}$ It was found that the higher the intensity of phosphatidylserine on the surface of tumor cell line, the more improved is the targeting of SA-based liposome to tumor cell. Moreover, SA-based liposomes could induce apoptosis on cancerous cells even without the incorporation of an anticancer drug. This was attributed to the strong affinity between the positively charged SA on the liposomal surface and the negatively charged phosphatidylserine on the cancerous cell surface. ${ }^{85}$ What further consolidate our findings was the fact that A549 tumor cell line belongs to a class of high phosphatidylserine expression rate. ${ }^{86}$

Those findings suggested the efficiency of incorporating curcumin into proliposomes as an anticancer carrier. Possibly the enhanced efficacy was due to the improved cellular uptake of the liposomes as compared to the free drug, which was a sum of the reduced PS, improved targeting nature of liposomes, increased cancer cell affinity due to electrostatic interaction between SA and phosphatidylserine.

\section{Influence of the Tested Formulations on Pro-Inflammatory Cytokines}

The effect of curcumin on the three major inflammatory cytokines, TNF- $\alpha$, IL- 6 and IL-10 is represented in Figure $8 \mathrm{~B}$. Since these inflammatory markers are good indicatives of tumor progression besides tumor-induced inflammation, ${ }^{36}$ it was beneficial to study the possible outcomes of curcumin on their levels as well as to what extent the proposed formulations could alter those levels. Tumor-induced inflammation leads to activation of lung macrophages with subsequent release of numerous chemical cytokines, including TNF- $\alpha{ }^{87,88}$ As a result of ongoing severe inflammatory response, IL- 6 and the more potent IL-10 are also released. IL-6 is thought to enhance tumor cell activity ${ }^{89}$ while IL-10 is considered to be a major immunosuppressive pro-tumoral cytokine with enhancing effect on tumor growth. ${ }^{90}$ In conclusion, tissue damage as a result of severe inflammation occurs and possible DNA mutations take place which further helps with the progress of cancer. Hence, any positive lowering effect on such inflammatory cytokines is favorable to limit the progression of cancer. As shown in the figure, the examined samples lowered the levels of the three inflammatory cytokines significantly ( $\mathrm{P}<0.05)$ compared to the control. Additionally, the improved SD/P6 and SD/P4 were found to significantly lower $(\mathrm{P}<0.05)$ the levels of all the three inflammatory cytokines, as compared to free curcumin or non-medicated formulations. A notable finding was that the presence of PLX 188 in the improved SD/P6 led to a more lowering activity than in improved SD/P4 (lacking PLX 188). It was reported that PLX 188 is a potent inhibitor of P-gp which helps with reduced drug efflux from the cells which prolongs curcumin intracellular activity. ${ }^{91}$

\section{Lung Pharmacokinetic Studies}

Both improved formulations SD/P4 \& SD/P6 with acceptable aerodynamic properties and cytocompatibility were administered by intra-tracheal intubation. The lung pharmacokinetic parameters are summarized in Table 3 and the lung concentration-time curve is presented in Figure 9.

From the curve and the pharmacokinetic parameters, it can be noticed that the improved SD/P4 and SD/P6 exhibited shorter $\mathrm{T}_{\max }$, higher $(\mathrm{P}<0.05) \mathrm{C}_{\max }, \mathrm{AUC}_{(0-24)}$ and $\mathrm{AUC}_{(\mathrm{inf})}$ values compared to the free drug powder. These findings for the proliposomal formulations suggested a faster absorption rate than that for the free drug powder which might be attributed to the improved lung uptake due to the much smaller MMAD $(2.10 \pm 0.26 \mu \mathrm{m}$ and $3.18 \pm 0.29$ $\mu \mathrm{m}$ for the improved $\mathrm{SD} / \mathrm{P} 4$ and $\mathrm{SD} / \mathrm{P} 6$ versus $3.81 \pm 1.15$ $\mu \mathrm{m}$ for the free drug powder). Also, free curcumin has poor aqueous solubility, low tissue permeability and poor bioavailability. Higher lung residence time values for the improved $\mathrm{SD} / \mathrm{P} 4$ and $\mathrm{SD} / \mathrm{P} 6$ were noticed in comparison to the free drug as evident by the significantly higher $(\mathrm{p}<$ 0.05) MRT values. It is worth mentioning that $\mathrm{C}_{\max }$ and AUC values for the improved SD/P4 were significantly

Table 3 Different Lung Pharmacokinetic Parameters for Curcumin Powder and Curcumin Proliposomal Formulations

\begin{tabular}{|l|c|c|c|}
\hline Measured Parameter & Curcumin Powder & Improved SD/P4 & Improved SD/P6 \\
\hline$T_{\max }(\mathrm{h})$ & 2 & 1 & 1 \\
$\mathrm{C}_{\max }(\mathrm{ng} / \mathrm{mL})$ & $1232.50 \pm 247.57$ & $5052.35 \pm 1368.91$ & $3345.75 \pm 795.09$ \\
$\mathrm{AUC}_{(0-24)}(\mathrm{ng} . \mathrm{h} / \mathrm{mL})$ & $6908.69 \pm 978.93$ & $12.529 .63 \pm 1032.63$ & $9936.73 \pm 1368.68$ \\
$A \cup C_{(\mathrm{inf})}(\mathrm{ng} . \mathrm{h} / \mathrm{mL})$ & $7193.12 \pm 901.23$ & $19.708 .67 \pm 4602.45$ & $12.361 .21 \pm 2879.92$ \\
MRT $^{(h)}$ & $4.80 \pm 0.15$ & $7.50 \pm 0.17$ & $7.30 \pm 1.60$ \\
\hline
\end{tabular}




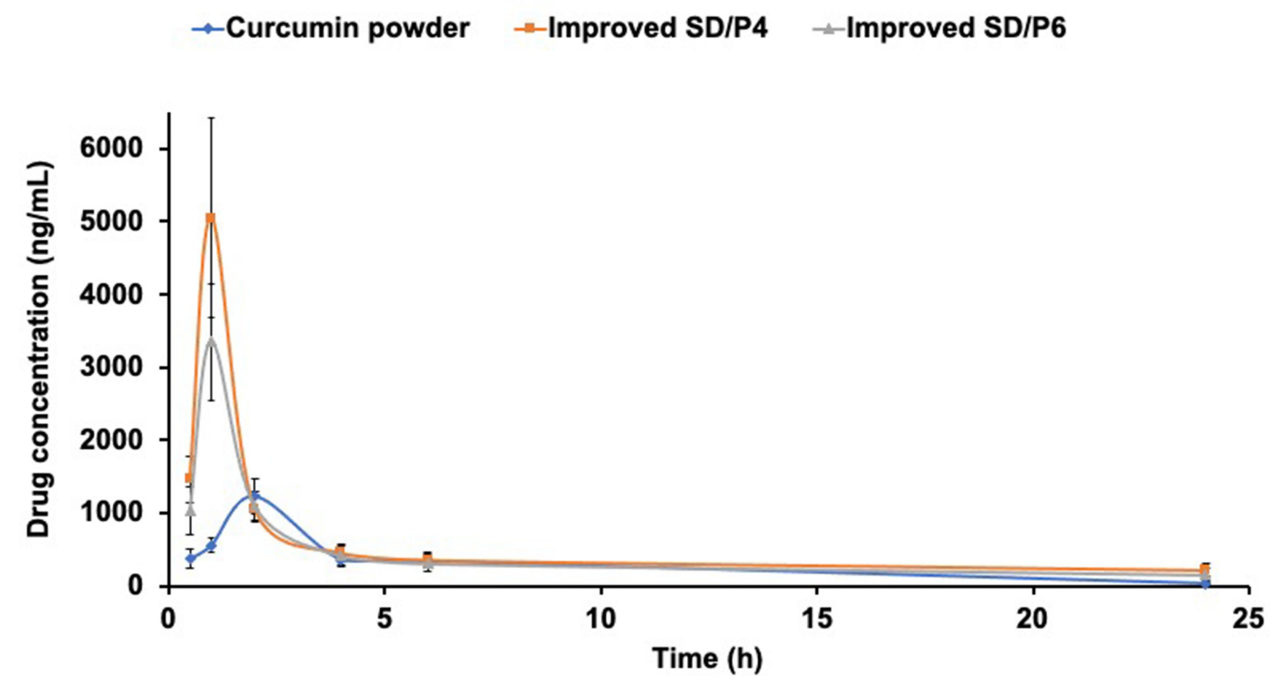

Figure 9 Lung concentration-time curve for curcumin-free powder and curcumin proliposomal formulations. The improved formulations exhibited shorter $\mathrm{T}_{\text {max }}$, higher $\mathrm{C}_{\max }, \mathrm{AUC}_{(0-24)}$ and $\mathrm{AUC}_{(\mathrm{inf})}$ values compared to the free curcumin powder $(\mathrm{P}<0.05)$. This suggests an enhancement in both the rate and extent of the improved formulation uptake by lung tissues as compared to the free curcumin.

higher $(\mathrm{p}<0.05)$ than those of the improved SD/P6. This is in line with the aerodynamic study findings concluding that the improved $\mathrm{SD} / \mathrm{P} 4$ is more promising as for further future studies.

\section{Conclusion}

In this study, spray-dried curcumin-loaded proliposomes were prepared using nano-spray dryer for pulmonary delivery. Lecithin, cholesterol, SA, PLX 188 were used for the fabrication of proliposomes as well as HP $\beta C D$ which was added as a carrier. The optimized spray-dried formulations showed promising results compared to curcumin powder in different tests. In the aerodynamic particle size analysis with cascade impactor, the much smaller particle size (nano range) with high \% FPF, made it feasible to reach deep lung tissues. Cytotoxicity studies were carried and MTT assay showed both, an improved growth inhibitory effect on lung tumor $\mathrm{A} 549$ cancer cells and low $\mathrm{IC}_{50}$ values, as compared to curcumin powder and plain formulations. The optimized formulations exerted a positive lowering effect on the main inflammatory cytokines (TNF- $\alpha$, IL-6 and IL-10) much higher than that achieved by curcumin powder or plain formulations. Lung pharmacokinetic studies showed that the improved formulations are more extensively and rapidly absorbed as well as more retained in the lung compared to the free curcumin powder and were generally in agreement with findings from aerodynamic studies. In general, the optimized formulations represent promising inhalation alternative for the treatment of cancer patients.

\section{Funding}

This research had not received any sort of funding from any organization, in the public or private sectors.

\section{Disclosure}

The authors report no conflicts of interest in this work.

\section{References}

1. Tomeh MA, Hadianamrei R, Zhao X. A review of curcumin and its derivatives as anticancer agents. Int $J$ Mol Sci. 2019;20(5):1033. doi:10.3390/ijms20051033

2. Wang K, Chen M, Wu W. Analysis of microRNA (miRNA) expression profiles reveals 11 key biomarkers associated with non-small cell lung cancer. World J Surg Oncol. 2017;15(1):175. doi:10.1186/s12957-0171244-y

3. Chen Y, Li J, Chen S, et al. Nab-Paclitaxel in combination with cisplatin versus docetaxel plus cisplatin as first-line therapy in non-small cell lung cancer. Sci Rep. 2017;7(1):10760. doi:10.1038/ s41598-017-11404-9

4. Zhang T, Chen Y, Ge Y, Hu Y, Li M, Jin Y. Inhalation treatment of primary lung cancer using liposomal curcumin dry powder inhalers. Acta Pharm Sin B. 2018;8(3):440-448. doi:10.1016/j.apsb.2018. 03.004

5. O'Callaghan DS, O'Donnell D, O'Connell F, O'Byrne KJ. The role of inflammation in the pathogenesis of non-small cell lung cancer. $J$ Thorac Oncol. 2010;5(12):2024-2036. doi:10.1097/JTO.0b013e318 $1 \mathrm{f} 387 \mathrm{e} 4$

6. Becker Y. Molecular immunological approaches to biotherapy of human cancers - A review, hypothesis and implications. Anticancer Res. 2006;26:1113-1134.

7. Diakos CI, Charles KA, McMillan DC, Clarke SJ. Cancer-related inflammation and treatment effectiveness. Lancet Oncol. 2014;15 (11):e493-e503. doi:10.1016/S1470-2045(14)70263-3 
8. Bonavita E, Galdiero MR, Jaillon S, Mantovani A. Chapter four phagocytes as corrupted policemen in cancer-related inflammation. In Wang X-Y, Fisher PT editors, Immunotherapy of Cancer. Vol. 128. Academic Press; 2015:141-171. doi:10.1016/bs.acr.2015.04.013

9. Munn LL. Cancer and inflammation. Wiley Interdiscip Rev Syst Biol Med. 2017;9(2). doi:10.1002/wsbm.1370

10. Stylianopoulos T, Martin JD, Chauhan VP, et al. Causes, consequences, and remedies for growth-induced solid stress in murine and human tumors. Proc Natl Acad Sci U S A. 2012;109 (38):15101-15108. doi:10.1073/pnas.1213353109

11. ElKasabgy NA, Adel IM, Elmeligy MF. Respiratory tract: structure and attractions for drug delivery using dry powder inhalers. AAPS PharmSciTech. 2020;21(7):238. doi:10.1208/s12249-020-01757-2

12. Jaroonwitchawan T, Chaicharoenaudomrung N, Namkaew J, Noisa P. Curcumin attenuates paraquat-induced cell death in human neuroblastoma cells through modulating oxidative stress and autophagy. Neurosci Lett. 2017;636:40-47. doi:10.1016/j.neulet.2016.10.050

13. Chaves MA, Pinho SC. Curcumin-loaded proliposomes produced by the coating of micronized sucrose: influence of the type of phospholipid on the physicochemical characteristics of powders and on the liposomes obtained by hydration. Food Chem. 2019;291:7-15. doi:10.1016/j.foodchem.2019.04.013

14. Giordano A, Tommonaro G. Curcumin and Cancer. Nutrients 2019;11(10):2376. doi:10.3390/nu11102376

15. Wan K, Sun L, Hu X, et al. Novel nanoemulsion based lipid nanosystems for favorable in vitro and in vivo characteristics of curcumin. Int J Pharm. 2016;504(1-2):80-88. doi:10.1016/j.ijpharm.2016.03. 055

16. Ghosh S, Banerjee S, Sil PC. The beneficial role of curcumin on inflammation, diabetes and neurodegenerative disease: a recent update. Food Chem Toxicol. 2015;83:111-124. doi:10.1016/j.fct.20 15.05 .022

17. Xu X-Y, Meng X, Li S, Gan R-Y, Li Y, Li H-B. Bioactivity, health benefits, and related molecular mechanisms of curcumin: current progress, challenges, and perspectives. Nutrients. 2018;10(10):1553. doi: $10.3390 /$ nu 10101553

18. Hu M, Du Q, Vancurova I, et al. Proapoptotic effect of curcumin on human neutrophils: activation of the p38 mitogen-activated protein kinase pathway. Crit Care Med. 2005;33(11):2571-2578. doi:10.10 97/01.CCM.0000186760.20502.C7

19. Nelson KM, Dahlin JL, Bisson J, Graham J, Pauli GF, Walters MA. The essential medicinal chemistry of curcumin. J Med Chem. 2017;60(5):1620-1637. doi:10.1021/acs.jmedchem.6b00975

20. Taylor TM, Weiss J, Davidson PM, Bruce BD. Liposomal nanocapsules in food science and agriculture. Crit Rev Food Sci Nutr. 2005;45(7-8):587-605. doi:10.1080/10408390591001135

21. Muneer S, Masood Z, Butt S, et al. Proliposomes as pharmaceutical drug delivery system: a brief review. J Text Sci Eng. 2017;08. doi:10.4172/2157-7439.1000448

22. Payne NI, Ambrose CV, Timmins P, Ward MD, Ridgway F. Proliposomes: a novel solution to an old problem. J Pharm Sci. 1986;75(4):325-329. doi:10.1002/jps.2600750402

23. Maged A, Mahmoud AA, Salah S, Abd-elmonsif NM, Ghorab MM. Spray-dried rosuvastatin nanoparticles for promoting hair growth. AAPS PharmSciTech. 2020;21(6):205. doi:10.1208/s12249-02001746-5

24. Karn PR, Jin S-E, Lee BJ, et al. Preparation and evaluation of cyclosporin A-containing proliposomes: a comparison of the supercritical antisolvent process with the conventional film method. Int J Nanomedicine. 2014;9:5079-5091. doi:10.2147/IJN.S70340

25. Khan KA, Rhodes CT. Effect of compaction pressure on the dissolution efficiency of some direct compression systems. Pharm Acta Helv. 1972;47(10):594-607.

26. Abdelrahim ME. Emitted dose and lung deposition of inhaled terbutaline from Turbuhaler at different conditions. Respir Med. 2010;104 (5):682-689. doi:10.1016/j.rmed.2009.11.014
27. Abdelrahim ME, Assi KH, Chrystyn H. Dose emission and aerodynamic characterization of the terbutaline sulphate dose emitted from a Turbuhaler at low inhalation flow. Pharm Dev Technol. 2013;18 (4):944-949. doi:10.3109/10837450.2011.620970

28. Ali AMA, Abdelrahim MEA. Modeling and optimization of terbutaline emitted from a dry powder inhaler and influence on systemic bioavailability using data mining technology. J Pharm Innov. 2014;9 (1):38-47. doi:10.1007/s12247-014-9171-8

29. Saeed H, Salem HF, Rabea H, Abdelrahim MEA. Effect of human error, inhalation flow, and inhalation volume on dose delivery from Ellipta $^{\circledR}$ dry-powder inhaler. J Pharm Innov. 2019;14(3):239-244. doi:10.1007/s12247-018-9352-y

30. Stationery Office. British pharmacopoeia 2016; 2015. Available from: https://books.google.com.eg/books?id=ukHasgEACAAJ. Accessed March 24, 2021.

31. Convention USP, Committees USPCC of E and its E, Committees USPCE. USP 39: the United States Pharmacopeia; NF 34: the national formulary: 2016. United States Pharmacopeial Convention; 2015. Available from: https://ci.nii.ac.jp/ncid/BB20598839. Accessed March 24, 2021.

32. Syed HK, Liew KB, Loh GOK, Peh KK. Stability indicating HPLCUV method for detection of curcumin in Curcuma longa extract and emulsion formulation. Food Chem. 2015;170:321-326. doi:10.1016/j. foodchem.2014.08.066

33. Elkasabgy NA, Abdel-Salam FS, Mahmoud AA, et al. Long lasting in-situ forming implant loaded with raloxifene $\mathrm{HCl}$ : an injectable delivery system for treatment of bone injuries. Int $J$ Pharm. 2019;571:118703. doi:10.1016/j.ijpharm.2019.118703

34. Salama AH, Abdelkhalek AA, Elkasabgy NA. Etoricoxib-loaded bio-adhesive hybridized polylactic acid-based nanoparticles as an intra-articular injection for the treatment of osteoarthritis. Int J Pharm. 2020;578:119081. doi:10.1016/j.ijpharm.2020.119081

35. Costa P. An alternative method to the evaluation of similarity factor in dissolution testing. Int J Pharm. 2001;220(1-2):77-83. doi:10. 1016/S0378-5173(01)00651-2

36. Mahmoud AA, Elkasabgy NA, Abdelkhalek AA. Design and characterization of emulsified spray dried alginate microparticles as a carrier for the dually acting drug roflumilast. Eur J Pharm Sci. 2018;122:64-76. doi:10.1016/j.ejps.2018.06.015

37. De Groote D, Gevaert Y, Lopez M, et al. Novel method for the measurement of cytokine production by a one-stage procedure. $J$ Immunol Methods. 1993;163(2):259-267. doi:10.1016/0022-175 9(93)90130-Y

38. De Groote D, Zangerle PF, Gevaert Y, et al. Direct stimulation of cytokines (IL-1 $\beta$, TNF- $\alpha$, IL-6, IL-2, IFN- $\gamma$ and GM-CSF) in whole blood. I. Comparison with isolated PBMC stimulation. Cytokine. 1992;4(3):239-248. doi:10.1016/1043-4666(92)90062-V

39. Hu Y, Li M, Zhang M, Jin Y. Inhalation treatment of idiopathic pulmonary fibrosis with curcumin large porous microparticles. Int J Pharm. 2018;551(1-2):212-222. doi:10.1016/j.ijpharm.2018.09.031

40. Morello M, Krone CL, Dickerson S, et al. Dry-powder pulmonary insufflation in the mouse for application to vaccine or drug studies. Tuberculosis. 2009;89(5):371-377. doi:10.1016/j.tube.2009.07.001

41. Shahin H, Vinjamuri BP, Mahmoud AA, Mansour SM, Chougule MB, Chablani L. Formulation and optimization of sildenafil citrate-loaded PLGA large porous microparticles using spray freeze-drying technique: a factorial design and in-vivo pharmacokinetic study. Int J Pharm. 2021;597:120320. doi:10.1016/j.ijpharm.20 21.120320

42. Loftsson T, Másson M, Brewster ME. Self-association of cyclodextrins and cyclodextrin complexes. J Pharm Sci. 2004;93(5):10 91-1099. doi:10.1002/jps.20047

43. Yadav VR, Suresh S, Devi K, Yadav S. Effect of cyclodextrin complexation of curcumin on its solubility and antiangiogenic and anti-inflammatory activity in rat colitis model. AAPS PharmSciTech. 2009;10(3):752-762. doi:10.1208/s12249-009-9264-8 
44. Dufour G, Bigazzi W, Wong N, et al. Interest of cyclodextrins in spray-dried microparticles formulation for sustained pulmonary delivery of budesonide. Int J Pharm. 2015;495:495. doi:10.1016/j. ijpharm.2015.09.052

45. Lu Z-R, Sakuma S. Nanomaterials in Pharmacology. Clifton: Humana Press; 2016. doi:10.1007/978-1-4939-3121-7

46. Gaul R, Ramsey JM, Heise A, Cryan S-A, Greene CM. Chapter 6 nanotechnology approaches to pulmonary drug delivery: targeted delivery of small molecule and gene-based therapeutics to the lung. In: Grumezescu AMBT-Design of Nanostructures for Versatile Therapeutic Applications. William Andrew Publishing; 2018:221-253. doi:10.1016/B978-0-12-813667-6.00006-1

47. Menon JU, Ravikumar P, Pise A, Gyawali D, Hsia CCW, Nguyen KT. Polymeric nanoparticles for pulmonary protein and DNA delivery. Acta Biomater. 2014;10(6):2643-2652. doi:10.1016/ j.actbio.2014.01.033

48. Levy ML, Carroll W, Izquierdo Alonso JL, Keller C, Lavorini F, Lehtimäki L. Understanding dry powder inhalers: key technical and patient preference attributes. Adv Ther. 2019;36(10):2547-2557. doi:10.1007/s12325-019-01066-6

49. Milani S, Faghihi H, Roulholamini Najafabadi A, Amini M, Montazeri H, Vatanara A. Hydroxypropyl beta cyclodextrin: a water-replacement agent or a surfactant upon spray freeze-drying of IgG with enhanced stability and aerosolization. Drug Dev Ind Pharm. 2020;46(3):403-411. doi:10.1080/03639045.2020.1724131

50. Loira-Pastoriza C, Todoroff J, Vanbever R. Delivery strategies for sustained drug release in the lungs. Adv Drug Deliv Rev. 2014;75:81-91. doi:10.1016/j.addr.2014.05.017

51. Shaker S, Gardouh AR, Ghorab M. Factors affecting liposomes particle size prepared by ethanol injection method. Res Pharm Sci. 2017;12:346. doi:10.4103/1735-5362.213979

52. Essa E. Effect of formulation and processing variables on the particle size of sorbitan monopalmitate niosome. Asian J Pharm. 2010;4:227. doi:10.4103/0973-8398.76752

53. Duangjit S, Pamornpathomkul B, Opanasopit P, et al. Role of the charge, carbon chain length, and content of surfactant on the skin penetration of meloxicam-loaded liposomes. Int $J$ Nanomedicine. 2014;9:2005-2017. doi:10.2147/IJN.S60674

54. Trivedi R, Kotgale NR, Taksande J, Wadher K, Awandekar NB, Umekar M. Influence of egg lecithin composition on physicochemical characteristics of pramipexole liposomes. Int J Res Pharm Sci. 2017;8:6-15.

55. Manjunath K, Venkateswarlu V, Hussain A. Preparation and characterization of nitrendipine solid lipid nanoparticles. Pharmazie. 2011;66(3):178-186. doi:10.1691/ph.2011.9373

56. Pamunuwa G, Karunaratne V, Karunaratne DN. Effect of lipid composition on in vitro release and skin deposition of curcumin encapsulated liposomes. J Nanomater. 2016;2016:4535790. doi:10.1155/ 2016/4535790

57. Carafa M, Santucci E, Lucania G. Lidocaine-loaded non-ionic surfactant vesicles: characterization and in vitro permeation studies. Int $J$ Pharm. 2002;231(1):21-32. doi:10.1016/S0378-5173(01)008 28-6

58. Chaudhari SP, Dugar RP. Application of surfactants in solid dispersion technology for improving solubility of poorly water soluble drugs. J Drug Deliv Sci Technol. 2017;41(June):68-77. doi:10.1016/ j.jddst.2017.06.010

59. ElShagea HN, ElKasabgy NA, Fahmy RH, Basalious EB. FreezeDried Self-Nanoemulsifying Self-Nanosuspension (SNESNS): a new approach for the preparation of a highly drug-loaded dosage form. AAPS PharmSciTech. 2019;20(7):258. doi:10.1208/s12249-019-14 $72-2$

60. Abd-Elsalam WH, ElKasabgy NA. Mucoadhesive olaminosomes: a novel prolonged release nanocarrier of agomelatine for the treatment of ocular hypertension. Int J Pharm. 2019;560:235-245. doi:10.1016/j.ijpharm.2019.01.070
61. Jiang J, Oberdörster G, Biswas P. Characterization of size, surface charge, and agglomeration state of nanoparticle dispersions for toxicological studies. J Nanoparticle Res. 2009;11(1):77-89. doi:10.1007/s11051-008-9446-4

62. Junyaprasert V, Teeranachaideekul V, Supaperm T. Effect of charged and non-ionic membrane additives on physicochemical properties and stability of niosomes. AAPS PharmSciTech. 2008;9:851-859. doi:10.1208/s12249-008-9121-1

63. Joseph E, Singhvi G. Chapter 4 - multifunctional nanocrystals for cancer therapy: a potential nanocarrier. In: Grumezescu AMBTNanomaterials for Drug Delivery and Therapy. William Andrew Publishing; 2019:91-116. doi:10.1016/B978-0-12-816505-8.00007-2

64. Müller R, Jacobs C, Kayser O. Nanosuspensions as particulate drug formulations in therapy. Rationale for development and what we can expect for the future. Adv Drug Deliv Rev. 2001;47:3-19. doi:10.1016/S0169-409X(00)00118-6

65. Hasan M, Elkhoury K, Kahn CJF, Arab-Tehrany E, Linder M. Preparation, characterization, and release kinetics of chitosan-coated nanoliposomes encapsulating curcumin in simulated environments. Molecules. 2019;24(10):2023. doi:10.3390/molecules24102023

66. Guo S, Xu ZB, Chen DQ, Liu JY. Encapsulation of curcumin into $\beta$ cyclodextrins inclusion: a review. E3S Web Conf. 2019;131:01100. doi:10.1051/e3sconf/201913101100

67. Gidwani B, Vyas A. A comprehensive review on cyclodextrin-based carriers for delivery of chemotherapeutic cytotoxic anticancer drugs. Biomed Res Int. 2015;2015:198268. doi:10.1155/2015/198268

68. Szejtli J. Introduction and general overview of cyclodextrin chemistry. Chem Rev. 1998;98(5):1743-1754. doi:10.1021/cr970022c

69. Usmani OS, Biddiscombe MF, Barnes PJ. Regional lung deposition and bronchodilator response as a function of $\beta 2$-agonist particle size. Am J Respir Crit Care Med. 2005;172(12):1497-1504. doi:10.1164/ rccm.200410-1414OC

70. Kreyling WG, Semmler-Behnke M, Seitz J, et al. Size dependence of the translocation of inhaled iridium and carbon nanoparticle aggregates from the lung of rats to the blood and secondary target organs. Inhal Toxicol. 2009;21(sup1):55-60. doi:10.1080/08958370902942517

71. Salem HF, Kharshoum RM, Abdel Hakim LF, Abdelrahim ME. Edge activators and a polycationic polymer enhance the formulation of porous voriconazole nanoagglomerate for the use as a dry powder inhaler. J Liposome Res. 2016;26(4):324-335. doi:10.3109/089821 04.2016 .1140182

72. Osama H, Sayed OM, Hussein RRS, Abdelrahim M, Elberry A. Design, optimization, characterization, and in vivo evaluation of sterosomes as a carrier of metformin for treatment of lung cancer. J Liposome Res. 2020;30(2):150-162. doi:10.1080/08982104.2019. 1610434

73. Chen X, Zou L, Niu J, Liu W, Peng S-F, Liu C-M. The Stability, Sustained Release and Cellular Antioxidant Activity of Curcumin Nanoliposomes. Molecules. 2015;20:14293-14311. doi:10.3390/ molecules200814293

74. Wulandari R, Martono S, Rohman A. Liquid chromatography and fourier transform infrared spectroscopy for quantitative analysis of individual and total curcuminoid in Curcuma longa extract. $J$ Appl Pharm Sci. 2018;8:107-113. doi:10.7324/JAPS.2018.8916

75. Chen J, Qin X, Zhong S, Chen S, Su W, Liu Y. Characterization of curcumin/cyclodextrin polymer inclusion complex and investigation on its antioxidant and antiproliferative activities. Molecules. 2018;23 (5):1179. doi:10.3390/molecules23051179

76. Kuligowski J, Quintas G, Esteve-Turrillas F, Garrigues S, Guardia M. On-line gel permeation chromatography-attenuated total reflectance-Fourier transform infrared determination of lecithin and soybean oil in dietary supplements. J Chromatogr A. 2008; 1185:71-77. doi:10.1016/j.chroma.2008.01.048

77. Gupta U, Singh V, Kumar V, Khajuria Y. Spectroscopic studies of cholesterol: fourier transform infra-red and vibrational frequency analysis. Mater Focus. 2014;3:1-7. doi:10.1166/mat.2014.1161 
78. El-Zawahry MM, Abdelghaffar F. Preparation and characterisation of novel phospholipid cationic liposomes to improve the alkaline hydrolysis and dyeability of polyester fabric. Color Technol. 2013;129 (3):193-202. doi:10.1111/cote.12024

79. Garala K, Joshi P, Shah M, Ramkishan A, Patel J. Formulation and evaluation of periodontal in situ gel. Int $J$ Pharm Investig. 2013;3:29-41. doi:10.4103/2230-973X.108961

80. Li W, Ran L, Liu F, et al. Preparation and characterisation of polyphenol-HP- $\beta$-cyclodextrin inclusion complex that protects lamb tripe protein against oxidation. Molecules. 2019;24(24):4487. doi:10.3390/ molecules 24244487

81. Khatun B, Baishya P, Ramteke A, Maji TK. Study of the complexation of structurally modified curcumin with hydroxypropyl beta cyclodextrin and its effect on anticancer activity. $N \mathrm{~J}$ Chem. 2020;44(12):4887-4897. doi:10.1039/C9NJ04408F

82. Fugita RA, Gálico DA, Guerra R, et al. Thermal behaviour of curcumin. Braz J Therm Anal. 2012;1:19-23.

83. Fernández-Romero A-M, Maestrelli F, Mura PA, Rabasco AM, González-Rodríguez ML. Novel findings about double-loaded curcumin-in-hpßcyclodextrin-in liposomes: effects on the lipid bilayer and drug release. Pharmaceutics. 2018;10(4):256. doi:10.3390/ pharmaceutics 10040256

84. Ekdahl A, Mudie D, Malewski D, Amidon G, Goodwin A. Effect of spray-dried particle morphology on mechanical and flow properties of felodipine in PVP VA amorphous solid dispersions. J Pharm Sci. 2019;108(11):3657-3666. doi:10.1016/j.xphs.2019.08.008
85. De M, Ghosh S, Sen T, et al. A novel therapeutic strategy for cancer using phosphatidylserine targeting stearylamine-bearing cationic liposomes. Mol Ther. 2018;10:9-27. doi:10.1016/j.omtn.2017.10.019

86. Zhao S, Chu Z, Blanco VM, Nie Y, Hou Y, Qi X. SapC-DOPS Nanovesicles as Targeted Therapy for Lung Cancer. Mol Cancer Ther. 2015;14(2):491LP- 498. doi:10.1158/1535-7163.MCT-14-0661

87. Barnes PJ. Alveolar macrophages as orchestrators of COPD. COPD J Chronic Obstr Pulm Dis. 2004;1(1):59-70. doi:10.1081/COPD120028701

88. Barnes PJ. The cytokine network in chronic obstructive pulmonary disease. Am J Respir Cell Mol Biol. 2009;41(6):631-638. doi:10.1165/rcmb.2009-0220TR

89. Guo Y, Xu F, Lu T, Duan Z, Zhang Z. Interleukin-6 signaling pathway in targeted therapy for cancer. Cancer Treat Rev. 2012;38 (7):904-910. doi:10.1016/j.ctrv.2012.04.007

90. Hatanaka H, Abe Y, Naruke M, et al. Significant correlation between interleukin 10 expression and vascularization through angiopoietin/ TIE2 networks in non-small cell lung cancer. Clin Cancer Res. 2001;7(5):1287LP-1292LP.

91. Huang J, Si L, Jiang L, Fan Z, Qiu J, Li G. Effect of pluronic F68 block copolymer on P-glycoprotein transport and CYP3A4 metabolism. Int J Pharm. 2008;356(1-2):351-353. doi:10.1016/j. ijpharm.2007.12.028
International Journal of Nanomedicine

\section{Publish your work in this journal}

The International Journal of Nanomedicine is an international, peerreviewed journal focusing on the application of nanotechnology in diagnostics, therapeutics, and drug delivery systems throughout the biomedical field. This journal is indexed on PubMed Central, MedLine, CAS, SciSearch ${ }^{\circledR}$, Current Contents ${ }^{\circledR} /$ Clinical Medicine,

\section{Dovepress}

Journal Citation Reports/Science Edition, EMBase, Scopus and the Elsevier Bibliographic databases. The manuscript management system is completely online and includes a very quick and fair peer-review system, which is all easy to use. Visit http://www.dovepress.com/ testimonials.php to read real quotes from published authors. 